\title{
The Level 2 research product algorithms for the Superconducting Submillimeter-Wave Limb-Emission Sounder (SMILES)
}

\author{
P. Baron ${ }^{1}$, J. Urban ${ }^{2}$, H. Sagawa ${ }^{1}$, J. Möller ${ }^{2}$, D. P. Murtagh ${ }^{2}$, J. Mendrok ${ }^{3}$, E. Dupuy ${ }^{1}$, T. O. Sato ${ }^{1,4}$, S. Ochiai ${ }^{1}$, \\ K. Suzuki ${ }^{1}$, T. Manabe ${ }^{5}$, T. Nishibori ${ }^{6}$, K. Kikuchi ${ }^{1,6}$, R. Sato ${ }^{6}$, M. Takayanagi ${ }^{6}$, Y. Murayama ${ }^{1}$, M. Shiotani ${ }^{7}$, and \\ Y. Kasai ${ }^{1}$ \\ ${ }^{1}$ National Institute of Information and Communications Technology, 4-2-1 Nukui-kitamachi, Koganei, \\ Tokyo, 184-8795, Japan \\ ${ }^{2}$ Department of Earth and Space Sciences, Chalmers University of Technology, 41296 Göteborg, Sweden \\ ${ }^{3}$ Department of Computer Science, Electrical and Space Engineering, Luleå University of Technology, 98128 Kiruna, Sweden \\ ${ }^{4}$ Tokyo Institute of Technology, 4259 Nagatsuta-cho, Midori-ku, Yokohama, Kanagawa, 226-8503, Japan \\ ${ }^{5}$ Osaka Prefecture University, 1-1 Gakuen-cho, Nakaku, Sakai, Osaka, 599-8531, Japan \\ ${ }^{6}$ Japan Aerospace Exploration Agency (JAXA), 2-1-1 Sengen, Tsukuba, Ibaraki, 305-8505, Japan \\ ${ }^{7}$ Research Institute for Sustainable Humanosphere, Kyoto University, Uji, Kyoto, 611-0011, Japan
}

Received: 8 April 2011 - Published in Atmos. Meas. Tech. Discuss.: 9 June 2011

Revised: 27 September 2011 - Accepted: 28 September 2011 - Published: 11 October 2011

\begin{abstract}
This paper describes the algorithms of the level2 research (L2r) processing chain developed for the Superconducting Submillimeter-Wave Limb-Emission Sounder (SMILES). The chain has been developed in parallel to the operational chain for conducting researches on calibration and retrieval algorithms. L2r chain products are available to the scientific community. The objective of version 2 is the retrieval of the vertical distribution of trace gases in the altitude range of $18-90 \mathrm{~km}$. A theoretical error analysis is conducted to estimate the retrieval feasibility of key parameters of the processing: line-of-sight elevation tangent altitudes (or angles), temperature and ozone profiles. While pointing information is often retrieved from molecular oxygen lines, there is no oxygen line in the SMILES spectra, so the strong ozone line at $625.371 \mathrm{GHz}$ has been chosen. The pointing parameters and the ozone profiles are retrieved from the line wings which are measured with high signal to noise ratio, whereas the temperature profile is retrieved from the optically thick line center. The main systematic component of the retrieval error was found to be the neglect of the non-linearity of the radiometric gain in the calibration procedure. This causes a temperature retrieval error of 5-10 K. Because of these large temperature errors, it is not possible to construct a reliable hydrostatic pressure profile. However, as a consequence of
\end{abstract}

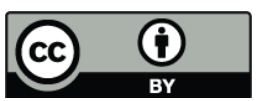

Correspondence to: P. Baron (baron@ nict.go.jp) the retrieval of pointing parameters, pressure induced errors are significantly reduced if the retrieved trace gas profiles are represented on pressure levels instead of geometric altitude levels. Further, various setups of trace gas retrievals have been tested. The error analysis for the retrieved $\mathrm{HOCl}$ profile demonstrates that best results for inverting weak lines can be obtained by using narrow spectral windows.

\section{Introduction}

The Superconducting Submillimeter-Wave Limb-Emission Sounder (SMILES) is a highly sensitive radiometer used to study atmospheric chemistry with a focus on the stratosphere (Kikuchi et al., 2010). It was developed by the Japan Aerospace Exploration Agency (JAXA) and the National Institute of Information and Communications Technology (NICT, Japan). Observations were performed from the Japanese Experiment Module (JEM) onboard the International Space Station (ISS) from October 2009 to April 2010. During that period, SMILES successfully measured the vertical distribution and the diurnal variations of various stratospheric and mesospheric species in the latitude range of $38^{\circ} \mathrm{S}-65^{\circ} \mathrm{N}$.

The SMILES operational ground segment was developed to calibrate the raw spectrometer outputs (i.e. level0 data) to radiances (i.e. level- $1 \mathrm{~b}$ data), and to retrieve the

Published by Copernicus Publications on behalf of the European Geosciences Union. 

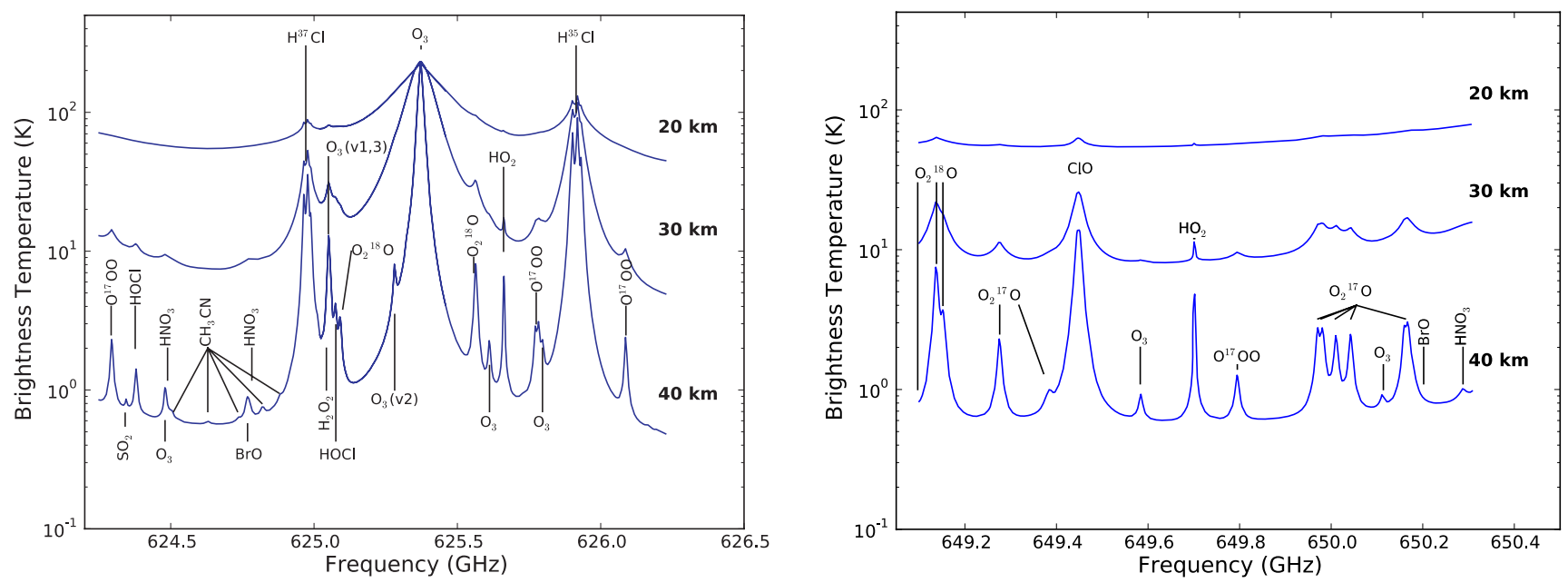

Fig. 1. Spectral lines from simulated limb radiances in bands A and B (left panel) and in band C (right panel). The line-of-sight tangent heights are 20, 30 and $40 \mathrm{~km}$.

geophysical products (i.e. level-2 data) (Takahashi et al., 2010). Daily maps are also available (http://smiles.nict.go. jp/index-e.html) and level-3 products (daily and monthly averaged data regridded to fixed geographical and vertical coordinates) are under development. In addition, NICT developed tools for research on calibration and retrieval algorithms leading to the development of a level- $1 \mathrm{~b}$ to level-2 chain, hereafter named Level-2 research (L2r) chain whose products are also available to the scientific community ${ }^{1}$.

This paper presents the retrieval algorithms used in the L2r chain. SMILES data processing benefits from the heritage of previous submillimeter missions: the SubMillimetre Radiometer (SMR) onboard the Odin satellite (2001-) (Murtagh et al., 2002) and the Microwave Limb Sounder (MLS) onboard the Aura satellite (2004-) (Waters et al., 2006). Their retrieval codes are described in Urban et al. (2005); Read et al. (2006); Livesey et al. (2006) and references therein. In the SMILES operational level-2 algorithm, the vertical profiles of geophysical parameters are simultaneously retrieved from the full spectra measured during a vertical scan of the atmospheric limb. In the L2r algorithm, the retrieval procedure has been divided into sequentially dependent processes in order to apply optimised retrieval settings to selected spectral lines in a given altitude range. Such approach allows to better characterise the spectra baseline and, hence, improves the results of the weak lines inversion. Another major difference between the operational and L2r algorithms is about the line-of-sight elevation angles treatment. Most of the prior microwave limb sounding instruments used a molecular oxygen line to retrieve the tangent points pressure (or elevation angles) which is a key parameter for limb-sounding (Carlotti and Rodolfi, 1999). There

${ }^{1}$ The SMILES data distribution policy is explained at http://smiles.tksc.jaxa.jp/ra/indexe.shtml. is no such line in the SMILES spectra. In the operational level-2 algorithm only a mean offset of the elevation angles is retrieved for each scan, while in the $\mathrm{L} 2 \mathrm{r}$ algorithms, the angles of each line-of-sight are retrieved using the strongest $\mathrm{O}_{3}$ line in the SMILES spectra.

In Sect. 2, a brief overview of the instrument and of the level-2 research chain is presented. The strategy for the retrieval procedure is presented in Sect. 3. The forward model used to simulate the measurements is described in Sect. 4. The inversion and the retrieval error characterisation methods are presented in Sect. 5. The performance of the retrieval approach is discussed in Sect. 6. We show results for the key parameters of the retrieval procedure: line-of-sight elevation angles, and temperature and $\mathrm{O}_{3}$ volume-mixing ratio (VMR) profiles. In order to illustrate the results obtained from a weak signal, the retrieval error of hypochlorous acid $(\mathrm{HOCl})$ is also discussed. Finally we conclude with a summary and an outlook on the future improvements and new products.

\section{Overview of the SMILES measurements and of the L2r chain}

SMILES observed spectral lines from the atmospheric limb in three frequency bands, named A $(624.3-625.5 \mathrm{GHz}), \mathrm{B}$ $(625.1-626.3 \mathrm{GHz})$ and $\mathrm{C}(649.1-650.3 \mathrm{GHz})$. Figure 1 shows synthetic spectra for line-of-sight tangent point altitudes of 20, 30 and $40 \mathrm{~km}$ and for the three bands (A and $\mathrm{B}$ in the upper panel and $\mathrm{C}$ in the lower panel). The strongest spectral signature is the $\mathrm{O}_{3}$ line at $625.371 \mathrm{GHz}$ common to bands A and B. Two strong triplets can be seen, one from $\mathrm{H}^{37} \mathrm{Cl}$ around $624.98 \mathrm{GHz}$ (band $\mathrm{A}$ ) and the other one from $\mathrm{H}^{35} \mathrm{Cl}$ around $625.92 \mathrm{GHz}$ (band $\mathrm{B}$ ). The other lines are significantly less intense. Two bands are measured 
Table 1. Characteristics of the SMILES antenna and the observation sequence.

\begin{tabular}{ll}
\hline $\begin{array}{l}\text { Antenna size } \\
\text { Antenna pattern (vertical } \\
\text { full width half maximum) }\end{array}$ & $0.09^{\circ}(\sim 4 \mathrm{~km}$ at the limb) \\
Total scan duration & $53 \mathrm{~s}$ \\
Atmospheric scan duration & $30.5 \mathrm{~s}$ \\
Vertical velocity & $0.1125^{\circ} \mathrm{s}^{-1}$ (upward direction) \\
Spectrum integration time & $0.5 \mathrm{~s}$ \\
Typical altitude coverage & -10 to $90 \mathrm{~km}(60$ spectra $)$ \\
Scans per day & $\sim 1630$ \\
\hline
\end{tabular}

simultaneously during a continuous vertical scan (Table 1) (Ochiai et al., 2010). The measurement of the emission from a hot and a cold load, and of a comb spectrum, are performed at the top of each scan for the radiance and the frequency calibration, respectively. The cold load is the cold sky at $2.7 \mathrm{~K}$ measured with the antenna pointing at tangent altitude of $\sim 200 \mathrm{~km}$ (above the atmosphere) while the hot load is an internal load at ambient temperature measured with a switching mirror. The atmospheric spectra are recorded every $0.5 \mathrm{~s}$ during the first $30.5 \mathrm{~s}$ of the scan, with line-of-sight tangent altitudes ranging typically from $-10 \mathrm{~km}$ to $90 \mathrm{~km}$.

The instrument is a single sideband heterodyne radiometer equipped with a $400 \times 200 \mathrm{~mm}$ elliptical antenna. The atmospheric signal is mixed with a local oscillator signal at $\nu_{\mathrm{lo}}=637.32 \mathrm{GHz}$ in a superconductor-insulatorsuperconductor (SIS) mixer cooled at $4 \mathrm{~K}$ which gives a very low receiver temperature of 300-350 K (Kikuchi and Fujii, 2010). The bands A and B lie in the lower sideband (LSB) of the local oscillator frequency and band $\mathrm{C}$ is in the upper sideband (USB). The signal is analysed by two acousto-optical spectrometers (AOS) with similar characteristics: 1728 channels separated by $0.8 \mathrm{MHz}$ with an effective spectral resolution of $1.4 \mathrm{MHz}$. The AOS channel frequency is calibrated for every scan and corrected from the Doppler shift of $\sim 8 \mathrm{MHz}$ caused by the ISS velocity component parallel to the line-of-sight $\left(\sim 4 \mathrm{~km} \mathrm{~s}^{-1}\right)$.

The data produced by the version 2 of the L2r chain are the vertical distributions of $\mathrm{O}_{3}$ and its main isotopes, two isotopomers of hydrochloric acid $\left(\mathrm{H}^{35} \mathrm{Cl}\right.$ and $\left.\mathrm{H}^{37} \mathrm{Cl}\right)$, chlorine and bromine monoxides $(\mathrm{ClO}, \mathrm{BrO})$, nitric acid $\left(\mathrm{HNO}_{3}\right)$, hydroperoxyl radical $\left(\mathrm{HO}_{2}\right)$, hypochlorous acid $(\mathrm{HOCl})$, hydrogen peroxide $\left(\mathrm{H}_{2} \mathrm{O}_{2}\right)$, and methyl cyanide $\left(\mathrm{CH}_{3} \mathrm{CN}\right)$. The main objective for version 2 algorithms is to retrieve data between 18 to $90 \mathrm{~km}$. Below $18 \mathrm{~km}$, the retrieved data are available but they are strongly affected by the errors on the calibrated radiances and on the modelling of the absorption continuum. They should be used with caution and the results will not be discussed in this paper.

The retrieval procedure is composed of sequentially dependent processes, each of them associated with a spectral

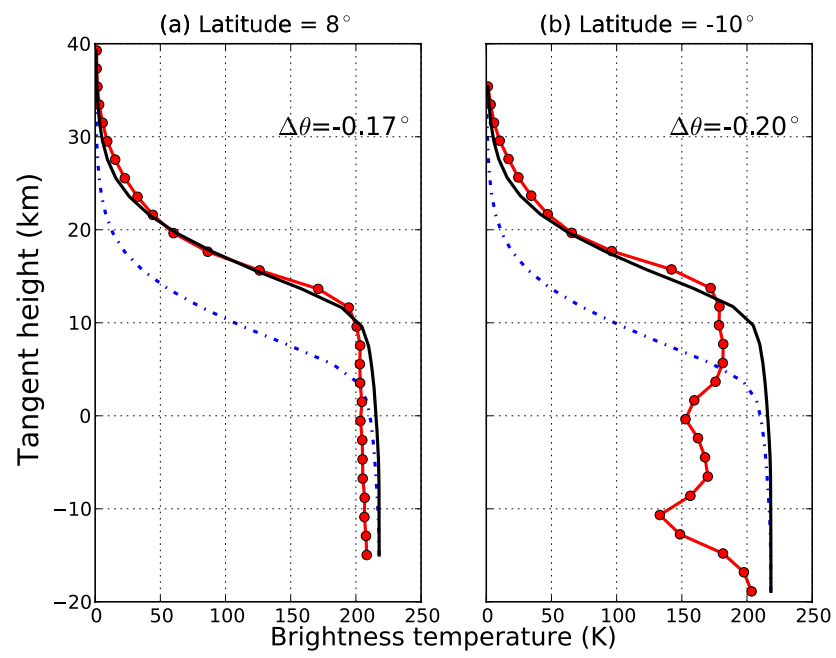

Fig. 2. Measured brightness temperature (red circles) with respect to corrected tangent heights at $624.547 \mathrm{GHz}$ : (a) clear sky case for a latitude of $8^{\circ} \mathrm{N}$, and (b) for a latitude of $10^{\circ} \mathrm{S}$ with scattering ice particles. The black line is a calculation using the line-of-sight tangent altitude corrected before the retrieval calculation and the blue dotted line is the calculation on the original line-of-sight tangent altitude. The correction is $-0.17^{\circ}$ (about $6 \mathrm{~km}$ ) for case (a) and $-0.19^{\circ}$ (about $7 \mathrm{~km}$ ) for case (b). Data are two single scans measured on 14 April 2010.

window and a line-of-sight altitude range. The processes are denoted by the name of the spectral band (A, B or C) and a window index (e.g. w1). The list of the processes is given in Table 2. The same parameter can be retrieved from different processes leading to different products that are defined by the parameter name (e.g. $\mathrm{O}_{3}$ or temperature) and by the process name (e.g. A-w1). The same forward and retrieval models are used for each process but the setting (e.g. position and size of the window, retrieval vertical grid, inversion regularisation parameters) is optimized according to the characteristics of the spectral lines of interest and of the altitude range. L2r products are distributed in daily files using the HDF-EOS format (http://www.hdfgroup.org/hdfeos.html).

\section{Retrieval strategy}

For limb observations at SMILES frequencies, the atmosphere is opaque at altitudes below typically 10 to $12 \mathrm{~km}$, depending on the upper tropospheric (UT) water vapor content. The right panel of Fig. 2 shows the variation with the lineof-sight tangent altitude of the measured brightness temperature at $624.547 \mathrm{GHz}$ (red line). For altitudes where the atmosphere is opaque, the brightness temperature reaches a saturated level at about $220 \mathrm{~K}$ : the measurement is not sensitive to the atmospheric conditions below about $12 \mathrm{~km}$. Scattering by ice particles can also occur in the UT yielding a clear depletion of the saturated brightness temperature (Fig. 2, right 
Table 2. SMILES L2 research data produced by the version-2 algorithms. The products list for each process or window is given along with the frequency range and the line-of-sight altitude range. The actual vertical range for a good retrieval depends on the signal strength.

\begin{tabular}{|c|c|c|c|}
\hline $\begin{array}{l}\text { Window/ } \\
\text { Process } \\
\text { name }\end{array}$ & Frequency & Products & $\begin{array}{r}\text { Line-of-sight } \\
\text { tangent height } \\
(\mathrm{km})\end{array}$ \\
\hline A-w0 & $625.042-625.612$ & Line of sight elevation angle & $18-70$ \\
\hline A-w1 & $625.042-625.612$ & Temperature, $\mathrm{O}_{3}, \mathrm{OO}^{18} \mathrm{O}$ & $18-100$ \\
\hline A-w2 & $624.445-625.040$ & $\mathrm{H}^{37} \mathrm{Cl}, \mathrm{HNO} 3, \mathrm{BrO}$ & $18-100$ \\
\hline A-w3 & $624.35-624.900$ & $\mathrm{BrO}, \mathrm{HNO} 3, \mathrm{CH}_{3} \mathrm{CN}, \mathrm{O}^{18} \mathrm{OO}$ & $25-80$ \\
\hline A-w4 & $625.015-625.185$ & $\mathrm{HOCl}, \mathrm{OO}^{18} \mathrm{O}, \mathrm{H}_{2} \mathrm{O}_{2}^{*}$ & $25-80$ \\
\hline A-w5 & $625.500-625.612$ & $\mathrm{OO}^{18} \mathrm{O}^{*}$ & $25-80$ \\
\hline A-w6 & $624.265-624.642$ & $\mathrm{O}^{17} \mathrm{OO}, \mathrm{HNO}_{3}$ & $20-70$ \\
\hline A-w7 & $625.132-625.232$ & $\mathrm{HOBr}^{*}$ & $20-70$ \\
\hline A-w8* & Full band & $\mathrm{O}_{3}, \mathrm{H}^{37} \mathrm{Cl}, \mathrm{BrO}, \mathrm{HNO}_{3}, \mathrm{CH}_{3} \mathrm{CN}, \mathrm{H}_{2} \mathrm{O}$ & $11-35$ \\
\hline B-w0 & $625.042-625.612$ & Line of sight elevation angle & $18-70$ \\
\hline B-w1 & $625.042-625.612$ & Temperature, $\mathrm{O}_{3}, \mathrm{OO}^{18} \mathrm{O}$ & $18-100$ \\
\hline B-w2 & $625.714-626.264$ & $\mathrm{H}^{35} \mathrm{Cl}, \mathrm{O}^{17} \mathrm{OO}$ & $16-100$ \\
\hline B-w3 & $625.015-625.185$ & $\mathrm{HOCl}, \mathrm{OO}^{18} \mathrm{O}, \mathrm{H}_{2} \mathrm{O}_{2}$ & $25-90$ \\
\hline B-w4 & $625.500-625.830$ & $\mathrm{HO}_{2}, \mathrm{OO}^{18} \mathrm{O}, \mathrm{O}^{17} \mathrm{OO}$ & $20-90$ \\
\hline B-w5 & $625.130-625.230$ & HOBr* & $25-80$ \\
\hline B-w6* & Full band & $\mathrm{O}_{3}, \mathrm{HNO}_{3}, \mathrm{H}^{35} \mathrm{Cl}, \mathrm{H}_{2} \mathrm{O}$ & $11-35$ \\
\hline $\mathrm{C}-\mathrm{w} 0^{*}$ & Full band & $\mathrm{O}_{3}, \mathrm{ClO}, \mathrm{HO}_{2}, \mathrm{HNO}_{3}, \mathrm{OO}^{18} \mathrm{O}, \mathrm{OO}^{17} \mathrm{O}, \mathrm{BrO}, \mathrm{H}_{2} \mathrm{O}$ & $11-40$ \\
\hline C-w1 & $649.882-650.382$ & $\mathrm{BrO}, \mathrm{HNO}_{3}, \mathrm{OO}^{17} \mathrm{O}$ & $18-90$ \\
\hline C-w2 & $649.500-649.900$ & $\mathrm{HO}_{2}, \mathrm{O}^{17} \mathrm{OO}$ & $25-90$ \\
\hline C-w3 & $649.232-649.632$ & $\mathrm{ClO}, \mathrm{OO}^{17} \mathrm{O}$ & $15-80$ \\
\hline
\end{tabular}

The *indicates data that are not recommended for use.

panel). Ice water content in the UT can be retrieved from these observations (Ekström et al., 2007; Wu et al., 2008; Mendrok et al., 2008), but it requires a special algorithm that is not implemented in the current processor. Retrieval diagnostics show that inversion of ice-contaminated spectra (typically below $18 \mathrm{~km}$ in the tropical regions) give bad results and that the retrieved data are not usable.

The line-of-sight tangent altitudes (or angles) are key parameters that should have been obtained by the star tracker attached to the instrument. However, the star tracker data have been found to be noisy in the level-1b data (version 5). Therefore the attitudes data based on the ISS Guidance, Navigation, and Control system are used instead. For each scan, the line-of-sight angles must be corrected for a global offset that can be as large as $0.2^{\circ}(8 \mathrm{~km}$ on the tangent point altitude). The correction is performed before the retrieval procedure by matching the measured brightness temperatures with the ones computed with the forward model (Sect. 4). The atmospheric inputs for the calculation are the temperature, pressure, $\mathrm{H}_{2} \mathrm{O}$ and $\mathrm{O}_{3}$ profiles from the version 5.2 of the analysis of the Goddard Earth Observing System Data Assimilation System model (GEOS-5.2) (Reinecker, 2008), and other species are from various climatologies. GEOS5 data are given every $6 \mathrm{~h}$ on $2 / 3 \times 1 / 2^{\circ}$ longitude-latitude horizontal grid. We have chosen to use the closest GEOS-5 profile to the middle of the scan of interest. Figure 2 shows the forward model calculation before (dashed line) and after (black solid line) line-of-sight angles correction.

Below typically $18 \mathrm{~km}$, pressure broadening leads to overlapping wings of spectral lines. Contributions from the atmospheric parameters are thus mixed and only a limited number of parameters can be retrieved. In this study, the distributions of $\mathrm{O}_{3}, \mathrm{H}_{2} \mathrm{O}, \mathrm{HCl}$ and $\mathrm{ClO}$ are retrieved from the full spectral band (bandwidth of $1.2 \mathrm{GHz}$ ). Temperature and pressure profiles are fixed parameters from GEOS-5, an uncertainty of $1 \mathrm{~K}$ is assumed on the temperature.

Above $18 \mathrm{~km}$, spectral lines of different atmospheric molecules are separated from each other and from the continuum radiation background. Between $20-50 \mathrm{~km}$, temperature can be retrieved from the optically thick central channels of the strongest $\mathrm{O}_{3}$ line at $625.371 \mathrm{GHz}$ (Baron et al., 2001). The $\mathrm{O}_{3}$ VMR profile and line-of-sight angles have distinct signatures on the wings of the spectral line: the line amplitude changes with VMR while the relative width of the line changes with the line-of-sight angle. This study shows that the low noise of the SMILES measurements allows us to distinguish and consequently to retrieve both parameters from the wings of the $\mathrm{O}_{3}$ line chosen for the temperature retrieval. 
The full retrieval procedure is composed of the following processes:

1. The line-of-sight elevation angles are retrieved between 20 and $50 \mathrm{~km}$ from the intense $\mathrm{O}_{3}$ line at $625.371 \mathrm{GHz}$ (A-w0 and B-w0 in Table 2). The spectral window between 625.042 and $625.612 \mathrm{GHz}$ is used both for bands $\mathrm{A}$ and $\mathrm{B}$. The line-of-sight elevation angles outside the retrieval vertical range are computed by linearly extrapolating the retrieved angles.

2. Temperature and $\mathrm{O}_{3}$ are retrieved above $18 \mathrm{~km}$ from the same spectral range used in step 1 (A-w1 and B-w1). Temperature is retrieved up to $\sim 60 \mathrm{~km}$ and $\mathrm{O}_{3}$ up to $90 \mathrm{~km}$. The isotope $\mathrm{OO}^{18} \mathrm{O}$ is also retrieved simultaneously from two small lines at 625.901 and $625.563 \mathrm{GHz}$.

3. The strong lines of $\mathrm{HCl}$ are inverted between $18-90 \mathrm{~km}$ in the spectral ranges $624.445-625.040 \mathrm{GHz}$ for $\mathrm{H}^{37} \mathrm{Cl}$ (A-w2) and 625.714-626.264 GHz (B-w2) for $\mathrm{H}^{35} \mathrm{Cl}$.

4. Then, measurements in a set of narrow windows (Table 2) are inverted to fit the weak lines in the middle stratosphere and mesosphere. Due to the errors on the calibration of the radiance (see Sect. 6), it has been chosen to not use the retrieved temperature and line-of-sight angles to invert the measurements in Band $\mathrm{C}$.

5. The full spectral bands between 12 and $30 \mathrm{~km}$ are processed separately to retrieve the $\mathrm{VMR}$ of $\mathrm{O}_{3}, \mathrm{H}_{2} \mathrm{O}, \mathrm{HCl}$ and $\mathrm{ClO}$ in the UT/lower stratosphere (LS).

\section{Forward model}

The measured signal is simulated from the computation of the specific intensity $I^{\mathrm{atm}}\left(\mathrm{W} \mathrm{m}^{-2} \mathrm{sr}^{-1} \mathrm{~Hz}^{-1}\right)$ of the outgoing atmospheric radiation and by taking into account the SMILES instrument characteristics, i.e. the antenna field of view, the AOS channel shape and the mixing of the upper and lower sidebands. Details on the forward model computation are presented in Urban et al. (2004) and Baron et al. (2008). In this section, we focus on the parameters relevant to the SMILES analysis. The measured power is transformed to brightness temperatures using the Rayleigh-Jeans linear approximation. For bands A and B that are both measured in the lower sideband, the brightness temperature $T^{\mathrm{a}, \mathrm{b}}$ measured in the $i$ th channel is:

$$
\begin{gathered}
T^{\mathrm{a}, \mathrm{b}}\left(\theta_{j}, v_{i}\right)=\frac{c^{2}}{2 k_{\mathrm{b}} v_{i}^{2}} \int_{\Delta \theta, \Delta v} G_{\mathrm{e}}^{\mathrm{ANT}}\left(\theta, \theta_{j}, \omega\right) g^{\mathrm{AOS}}\left(v^{\mathrm{lsb}}, v_{i}\right)(1) \\
\frac{\left(1-R^{\mathrm{lsb}}\left(v^{\mathrm{lsb}}\right)\right) I^{\mathrm{atm}}\left(v^{\mathrm{lsb}}, \theta\right)+R^{\mathrm{usb}}\left(v^{\mathrm{usb}}\right) I^{\mathrm{atm}}\left(v^{\mathrm{usb}}, \theta\right)}{1-R^{\mathrm{lsb}}\left(v^{\mathrm{lsb}}\right)+R^{\mathrm{usb}}\left(v^{\mathrm{usb}}\right)} d \theta d v^{\mathrm{lsb}},
\end{gathered}
$$

where $\theta_{j}$ is the mean elevation angle of the antenna during the spectrum integration, $\theta$ is the optical path elevation angle for the specific intensity calculation, $G_{\mathrm{e}}^{\mathrm{ANT}}$ is the effective vertical antenna pattern, $g^{\mathrm{AOS}}$ is the AOS channel response function (see Appendix A), $v_{i}$ is the frequency of the $i$-th channel, $v^{\text {lsb }}$ and $v^{\mathrm{usb}}=2 v_{\mathrm{lo}}-v^{\mathrm{lsb}}$ are the lower and upper bands frequencies, $R^{\text {usb }}$ and $R^{\text {lsb }}$ are the upper and lower sidebands rejection values (see Appendix B). The term before the integral operator is the Rayleigh-Jeans factor and the Boltzmann constant $k_{\mathrm{b}}=1.380662 \times 10^{-23} \mathrm{~J} \mathrm{~K}^{-1}$. The formula for band $\mathrm{C}$ radiance is obtained by interchanging the superscript labels usb and lsb.

The contribution of the image band has been neglected: $R^{\mathrm{usb}}=R^{\mathrm{lsb}}=0$. It will be shown in Sect. 5.2 that the impact of such simplification is small compared to current calibration errors. The atmosphere is assumed to be horizontally stratified and only the integration in the vertical direction is performed. The vertical effective antenna pattern $G_{\mathrm{e}}^{\mathrm{ANT}}\left(\theta, \theta_{j}, \omega\right)$ includes the rotation $\omega$ of the 2-D antenna pattern with respect to the line of sight, the integration over the azimuth angle of the 2-D antenna pattern and the vertical scanning motion (Shiotani et al., 2002, 40-52 pp.). The vertical integration range $\Delta \theta$ is -4.2 to $4.2^{\circ}$; The contribution from outside this range is removed in the calibration procedure.

The specific intensity is computed by solving the radiative transfer equation along the optical path:

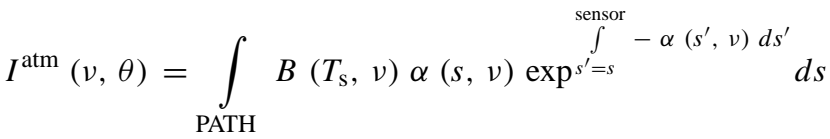

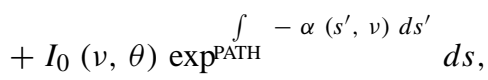

where $s$ and $s^{\prime}$ indicate the positions on the integration path, $\alpha$ is the absorption coefficient, $B(T, v)$ is the Planck function at temperature $T$ and $I_{0}$ is the background radiation (Earth surface, or cold space at the physical temperature of $2.7 \mathrm{~K}$ giving a brightness temperature of $4 \times 10^{-4} \mathrm{~K}$ ). The atmosphere is assumed to be in the hydrostatic equilibrium. Scattering and absorption from solid and liquid particles are not important for submillimeter wavelengths except in the presence of relatively thick clouds in the upper troposphere and thus not considered in our model. The bending of the optical path by atmospheric refraction is taken into account by using a non dispersive expression of the refractive index $n_{0}$ (Rüeger, 2002):

$n_{0}=1+10^{-8}\left(77.6890 \frac{P_{\mathrm{d}}}{T}+\frac{P_{\mathrm{w}}}{T}\left(71.2952+\frac{375463}{T}\right)\right)$,

where $P_{\mathrm{d}}$ and $P_{\mathrm{w}}$ are the dry air and water vapor partial pressures $(\mathrm{Pa})$. The dry air refractive contribution assumes a $\mathrm{CO}_{2}$ content of $375 \mathrm{ppm}$.

The absorption coefficient includes the spectral lines of relevant molecules and the absorption continua from dry air and water vapor. The continua parametrisation (Pardo 
et al., 2001) has been derived from atmospheric measurements at submillimeter wavelengths. It should be noted that at SMILES frequencies, the measured dry air continuum is $20-30 \%$ below theoretical estimations (Boissoles et al., 2003). Such error has a significant impact on the retrieved UT/LS data and should be checked in future versions.

The spectroscopic line shape is a Van-Vleck and Weisskopf (VVW) profile in the lower atmosphere where the line Doppler broadening is 40 times smaller than the collisional (pressure) broadening. At higher altitudes, a Voigt profile is used (Schreier and Kohlert, 2008). The collisional line broadening parameter includes the self-broadening parameter when available. The line frequency $v_{q}$ is shifted by the atmospheric pressure:

$v_{q}=\left(v_{q}^{0}+\delta_{v}^{q} P\left(\frac{T_{0}}{T}\right)^{n_{\mathrm{f}}}\right)$,

where $v_{q}^{0}$ is the line frequency and $\delta_{v}^{q}$ is the pressure induced frequency shift parameter at temperature $T_{0}$ and $n_{f}$ is its temperature dependence.

A catalogue of spectroscopic line parameters between 0 and $1 \mathrm{THz}$ has been created using parameters from the JPL catalogue (Pickett et al., 1998), completed with the line pressure-broadening and frequency pressure-shift parameters from the HITRAN database (Rothman et al., 2009). The parameters have been updated with the latest laboratory measurements (Table 3). Less than 1200 lines per band are considered in line-by-line calculations. The line selection algorithm selects all the lines inside the bands that have an intensity larger than $10^{-4} \mathrm{~K}$ between $15-90 \mathrm{~km}$ altitudes. The most significant out-of-band lines of $\mathrm{O}_{3}$ and $\mathrm{H}_{2} \mathrm{O}$ are selected in order to account for the contribution of their wings inside the band. For both molecules, selected out-of-band lines contribute to $99 \%$ of the absorption by all out-of-band lines considered. The same method is used for out-of-band lines of other molecules but the selection is performed for all species together and with a line selection threshold of $90 \%$. The line selection procedure selects a large number of relatively weak spectral lines located below $100 \mathrm{GHz}$ and a set of strong $\mathrm{O}_{2}$ lines at $\sim 60 \mathrm{GHz}$. These lines should not been selected since the computation of their absorption is overestimated at the SMILES frequency: (i) the VVW lineshape overestimates the absorption with an order of magnitude at frequencies larger than 5 times the resonant frequency (Harde et al., 1995), (ii) the actual $60 \mathrm{GHz}-\mathrm{O}_{2}$ lines absorption is reduced by a line mixing effect which is not taken into account in the calculation. Thus, all lines below $100 \mathrm{GHz}$ are rejected.

For reasons of efficiency, the absorption coefficients and the radiative transfer are computed on a non-equidistant frequency grid composed of less than 1500 points that is defined to avoid errors larger than $0.001 \mathrm{~K}$. These errors are estimated with the comparison of AOS radiances with those obtained with a fine frequency grid of $0.25 \mathrm{MHz}$ resolution.
Table 3. Values of the line frequency and of the air-broadening and pressure induced frequency shift parameters measured in laboratory. Only the main lines used in the processing are shown. Values not indicated are taken from the HITRAN (2008) database.

\begin{tabular}{|c|c|c|c|}
\hline Species & $\begin{array}{l}\text { line frequency } \\
(\mathrm{MHz})\end{array}$ & $\begin{array}{l}\text { air-broadening } \\
\text { (MHz/Torr)/ } \\
\text { temperature } \\
\text { dependence }\end{array}$ & $\begin{array}{l}\text { frequency } \\
\text { shift } \\
\text { (MHz/Torr) }\end{array}$ \\
\hline $\begin{array}{l}\mathrm{O}_{3} \\
\mathrm{O}_{3}\end{array}$ & $\begin{array}{l}625371.2420^{\mathrm{a}} \\
650732.7260\end{array}$ & $\begin{array}{l}3.08 / 0.73^{b} \\
3.01 / 0.60^{c}\end{array}$ & \\
\hline $\begin{array}{l}\mathrm{H}^{35} \mathrm{Cl} \\
\mathrm{H}^{35} \mathrm{Cl} \\
\mathrm{H}^{35} \mathrm{Cl}\end{array}$ & $\begin{array}{l}625901.6627^{d} \\
625918.7020^{d} \\
625931.9977^{d}\end{array}$ & $\begin{array}{l}3.39 / 0.72^{\mathrm{e}} \\
3.39 / 0.72^{\mathrm{e}} \\
3.39 / 0.72^{\mathrm{e}}\end{array}$ & $\begin{array}{l}0.145^{\mathrm{e}} \\
0.145^{\mathrm{e}} \\
0.145^{\mathrm{e}}\end{array}$ \\
\hline $\begin{array}{l}\mathrm{H}^{37} \mathrm{Cl} \\
\mathrm{H}^{37} \mathrm{Cl} \\
\mathrm{H}^{37} \mathrm{Cl}\end{array}$ & $\begin{array}{l}624964.3718^{d} \\
624977.8059^{d} \\
624988.2727^{d}\end{array}$ & $\begin{array}{l}3.39 / 0.72^{\mathrm{e}} \\
3.39 / 0.72^{\mathrm{e}} \\
3.39 / 0.72^{\mathrm{e}}\end{array}$ & $\begin{array}{l}0.145^{\mathrm{e}} \\
0.145^{\mathrm{e}} \\
0.145^{\mathrm{e}}\end{array}$ \\
\hline $\begin{array}{l}\mathrm{ClO} \\
\mathrm{ClO}\end{array}$ & $\begin{array}{l}649445.0400 \\
649451.1700\end{array}$ & $\begin{array}{l}2.86 / 0.77^{\mathrm{e}} \\
2.86 / 0.77^{\mathrm{e}}\end{array}$ & \\
\hline $\begin{array}{l}\mathrm{HO}_{2} \\
\mathrm{HO}_{2}\end{array}$ & $\begin{array}{l}625660.3542 \\
649701.4773\end{array}$ & $\begin{array}{l}3.77^{\mathrm{e} /} \\
2.74^{\mathrm{f}} /\end{array}$ & \\
\hline $\mathrm{H}_{2} \mathrm{O}_{2}$ & 625044.1800 & $3.71 / \mathrm{g}$ & \\
\hline $\mathrm{HOCl}$ & 625075.1346 & $3.88 / 0.65^{\mathrm{h}}$ & $-0.076^{\mathrm{h}}$ \\
\hline $\begin{array}{l}\mathrm{BrO} \\
\mathrm{BrO}\end{array}$ & $\begin{array}{l}624764.8570 \\
650175.8041\end{array}$ & $\begin{array}{l}3.05 / 0.80^{\mathrm{i}} \\
3.03 / 0.81^{\mathrm{i}}\end{array}$ & \\
\hline $\begin{array}{l}\mathrm{CH}_{3} \mathrm{CN} \\
\mathrm{CH}_{3} \mathrm{CN}\end{array}$ & $\begin{array}{l}624819.3573 \\
624926.4662\end{array}$ & $\begin{array}{l}4.79^{\mathrm{b}} / \\
4.81^{\mathrm{b} /}\end{array}$ & \\
\hline $\begin{array}{l}\mathrm{H}_{2} \mathrm{O} \\
\mathrm{H}_{2} \mathrm{O} \\
\mathrm{H}_{2} \mathrm{O}\end{array}$ & $\begin{array}{l}556936.0020 \\
620700.8070 \\
752033.2270\end{array}$ & $\begin{array}{l}4.01^{\mathrm{j} /} \\
4.38^{1} / \\
3.96^{\mathrm{j} /}\end{array}$ & $\begin{array}{l}0.300^{\mathrm{k}} \\
-0.031^{1} \\
0.197^{\mathrm{j}}\end{array}$ \\
\hline
\end{tabular}

a Laboratory measurements by H. Ozeki (SMILES team, personal communication,

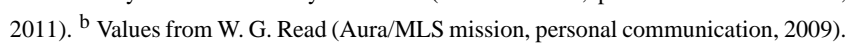
The broadening parameter of $\mathrm{O}_{3}$ at $625.371 \mathrm{MHz}$ is multiplied by an empirically derived correction factor of $5 \%$. ${ }^{\mathrm{c}}$ Laboratory measurements by Drouin and Gamache (2008). ${ }^{\mathrm{d}}$ Laboratory measurements by Cazzoli and Puzzarini (2004). ${ }^{\mathrm{e}}$ Laboratory measurements by A. Mizoguchi (Tokyo Institute of Technology, personal communication, 2009). ${ }^{\mathrm{f}}$ Laboratory measurements by M. Yamada (Ibaraki University, personal communication, 2009). ${ }^{\mathrm{g}}$ Laboratory measurements by Sato et al. (2010). ${ }^{\mathrm{h}}$ Laboratory measurements by Drouin (2007). ${ }^{\mathrm{i}}$ Laboratory measurements by Yamada et al. (2003). ${ }^{\mathrm{j}}$ Laboratory measurements by Hoshina et al. (2008). ${ }^{\mathrm{k}}$ Laboratory measurements by Markov and Krupnov (1995). ${ }^{1}$ Laboratory measurements by Y. Irimajiri (SMILES team, personnal communication, 2009).

\section{Methodology for the inversion and for the errors characterisation}

\subsection{Inversion method}

Within each retrieval process, a least-squares method with regularisation is used to seek for the forward model's 
unknown parameters $x$ that minimize the cost function $\chi^{2}$. The latter is given by

$\chi^{2}=\frac{(\boldsymbol{y}-\boldsymbol{F}(\boldsymbol{x}, \boldsymbol{b}))^{T} \mathbf{S}_{y}^{-1}(\boldsymbol{y}-\boldsymbol{F}(\boldsymbol{x}, \boldsymbol{b}))+\left(\boldsymbol{x}_{\mathrm{a}}-\boldsymbol{x}\right)^{T} \mathbf{S}_{\mathrm{a}}^{-1}\left(\boldsymbol{x}_{\mathrm{a}}-\boldsymbol{x}\right)}{n_{y}+n_{x}}$

where $\boldsymbol{y}$ is the measurement vector of $n_{y}$ elements, $\mathbf{S}_{y}$ is the measurement covariance matrix, $\boldsymbol{F}(\boldsymbol{x}, \boldsymbol{b})$ is the forward model (Eq. 1) depending on $\boldsymbol{x}$ and on the known model parameters $\boldsymbol{b}, n_{x}$ is the size of the vector $\boldsymbol{x}, \boldsymbol{x}_{\mathrm{a}}$ is the a priori value of $\boldsymbol{x}$ and $\mathbf{S}_{\mathrm{a}}$ the a priori covariance matrix. The a priori term corresponds to $n_{x}$ additional virtual measurements used to regularize the inversion process (Rodgers, 2000). The offdiagonal elements of $\mathbf{S}_{y}$ are assumed to be zero and the diagonal elements are set to the square of the thermal noise level. For SMILES, the latter is determined using the following form of the radiometric noise equation:

$\epsilon_{n}=\frac{T_{\mathrm{rec}}\left(v_{i}\right)+T\left(v_{i}, \theta\right)}{\sqrt{\beta \mathrm{d} \tau}}$,

with the receiver temperature (noise power generated by the receiver), $T_{\text {rec }}$, between $300-350 \mathrm{~K}$, the atmosphere temperature received by the antenna (Eq. 1), $T$, between $0-250 \mathrm{~K}$, the noise-equivalent spectral resolution $\beta=2.5 \mathrm{MHz}$, and the integration time of a single spectrum $\mathrm{d} \tau=0.5 \mathrm{~s}$. The actual measurement noise is thus $\sim 0.3 \mathrm{~K}$ but a fixed value of $0.5 \mathrm{~K}$ is used in this analysis.

The a priori covariance matrix is built using an a priori error $\epsilon_{\mathrm{a}}$ that does not correspond to the natural variability of $\boldsymbol{x}$, but to the measurement sensitivity. For instance, a large value of $\epsilon_{\mathrm{a}}$ (between 100-200\% of a typical profile) is used for species such as $\mathrm{BrO}$ or $\mathrm{H}_{2} \mathrm{O}_{2}$ that are retrieved from weak noisy lines. The retrieved profiles are then noisy and must be averaged to increase the precision. An altitude correlation in the a priori covariance matrix is used for each product according to the vertical resolution estimated from preliminary sensitivity studies (see Sect. 5.2). The scale-length of autoregressive correlation is between 2 and $6 \mathrm{~km}$. The a priori value of $\mathrm{O}_{3}, \mathrm{H}_{2} \mathrm{O}$ and temperature/pressure are from the GEOS-5 analysis (see Sect. 3). As the version of GEOS-5 model used in this analysis is valid below about $70 \mathrm{~km}$, the temperature and pressure profiles are extrapolated to $110 \mathrm{~km}$ using the MSIS temperature climatology (Hedin, 1991) with a method similar to that used for the Odin/SMR level-2 processing. Other GEOS-5 profiles are extrapolated with a constant value. Other species are described by a single profile obtained from different climatologies, and a large a priori error is assigned to these data. Table 4 summarizes the a priori data used in the processing.

To solve Eq. (2), the vector $\boldsymbol{x}$ is scaled with respect to $\boldsymbol{x}_{\mathrm{a}}$ and to the a priori error $\epsilon_{\mathrm{a}}$ :

$\boldsymbol{\eta}=\left(\boldsymbol{x}-\boldsymbol{x}_{\mathrm{a}}\right) / \boldsymbol{\epsilon}_{\mathrm{a}}$.
Table 4. Summary of the a priori information used in the a priori covariance matrix (Eq. 6). Errors and scale-length of autoregressive correlations are not representative of the real data, but are inversion regularisation parameters. Values for $\mathrm{O}_{3}$ are given for the inversion of the $625.371 \mathrm{GHz}$ line and those for $\mathrm{H}_{2} \mathrm{O}$ are for the full spectral band inversion.

\begin{tabular}{llll}
\hline & origin & error & correlation \\
\hline Line-of-sight elevation angles & ISS attitudes & $0.02^{\circ}$ & \\
Scan frequency offset & Comb spectra & $0.02 \mathrm{MHz}$ & \\
Temperature below $60 \mathrm{~km}$ & GEOS-5 & $5 \mathrm{~K}$ & $6 \mathrm{~km}$ \\
Temperature above $60 \mathrm{~km}$ & MSIS & $5 \mathrm{~K}$ & $6 \mathrm{~km}$ \\
$\mathrm{H}_{2} \mathrm{O}$ & GEOS-5 & $5 \mathrm{ppmv}$ & $6 \mathrm{~km}$ \\
$\mathrm{O}_{3}$ & GEOS-5 & 5 ppmv & $3 \mathrm{~km}$ \\
$\mathrm{HCl}$ & US standard & $>50 \%$ & $4 \mathrm{~km}$ \\
other species & climatology & signal & $3-6 \mathrm{~km}$ \\
& & strength & \\
& & dependent & \\
\hline
\end{tabular}

The solution is found with a Gauss-Newton iterative procedure modified by Levenberg (Rodgers, 2000, Chap. 5.7, Eq. 5.35).

$$
\begin{aligned}
\boldsymbol{\eta}_{i+1}=\boldsymbol{\eta}_{i}+ & \left(\mathbf{K}_{i}^{T} \mathbf{S} y^{-1} \mathbf{K}_{i}+\mathbf{S} \eta^{-1}+\gamma \mathbf{I}\right)^{-1} \\
& \left(\mathbf{K}^{T} \mathbf{S} y^{-1}\left(\boldsymbol{y}-\boldsymbol{F}_{i}\right)-\mathbf{S} \eta^{-1} \boldsymbol{\eta}_{i}\right),
\end{aligned}
$$

where the subscripts $i$ and $i+1$ indicate the iteration stage, $\mathbf{F}_{i}$ is the forward model output for $\boldsymbol{x}=\boldsymbol{x}_{i}, \mathbf{K}_{i}=\left(\frac{\partial \boldsymbol{F}}{\partial \eta}\right)_{i}$ is the weighting function matrix, $\mathbf{S}_{\eta}$ is the covariance matrix of the scaled vector $\boldsymbol{\eta}, \gamma$ is the Levenberg-Marquardt parameter and $\mathbf{I}$ is a diagonal scaling matrix. The diagonal elements of $\mathbf{I}$ are set to 1, except for the components of $\boldsymbol{x}$ that have a small impact on the $\chi^{2}$ and for which the value is zero. The a priori state of $\boldsymbol{\eta}$ is zero and it is not written in Eq. (5). The covariance matrix $\mathbf{S}_{\eta}$ is derived from the a priori covariance matrix as:

$$
\mathbf{S}_{\eta}=\mathbf{D}\left(1 / \boldsymbol{\epsilon}_{\mathrm{a}}\right) \mathbf{S}_{\mathrm{a}} \mathbf{D}\left(1 / \boldsymbol{\epsilon}_{\mathrm{a}}\right)^{T},
$$

with $\mathbf{D}\left(1 / \boldsymbol{\epsilon}_{\mathrm{a}}\right)$ the diagonal matrix with diagonal elements equal to the vector $1 / \boldsymbol{\epsilon}_{\mathrm{a}}$. The weighting function matrix $\mathbf{K}_{i}$ is related to the Jacobian matrix of the unscaled parameters as below:

$\mathbf{K}_{i}[m, n]=\left(\frac{\partial F[m]}{\partial x[n]}\right)_{i} \epsilon_{\mathrm{a}}[m]$,

where $m$ and $n$ are the measurement and parameters indexes, respectively.

If temperature is retrieved, the pressure profile can be derived from the hydrostatic equilibrium using a known pressure and temperature at a reference altitude. We use a reference altitude of $18 \mathrm{~km}$ and data from the GEOS-5 analysis. The pressure profile is computed above the reference altitude 
on a fine resolution vertical grid of $100 \mathrm{~m}$. The temperature profile is linearly interpolated on this fine grid and the discrete hydrostatic equation becomes:

$$
\frac{P[i+1]-P[i]}{P[i]}=-g(\Phi)\left(1-\frac{\bar{z}[i]}{r(\Phi)}\right) \frac{M_{\mathrm{a}}}{R} \frac{z[i+1]-z[i]}{\bar{T}[i]},
$$

where $i$ and $i+1$ are the indices of two consecutive vertical levels, $P[i](\mathrm{hPa})$ is the pressure at the altitude $z_{i}(\mathrm{~m})$, $\Phi(\mathrm{rad})$ is the latitude angle, $r(\Phi)=6378130\left(1-\frac{\sin (\Phi)^{2}}{298.25}\right)$ is the effective Earth radius $(\mathrm{m}), g(\Phi)=9.80616(1-$ $\left.0.0026373 \cos (2 \Phi)+5.9 \times 10^{-6} \cos (2 \Phi)^{2}\right)$ is the gravity at the surface $\left(\mathrm{m} \mathrm{s}^{-2}\right), R=8.3145 \mathrm{~J} \mathrm{~K}^{-1} \mathrm{~mol}^{-1}$ is the gas constant, $M_{\mathrm{a}}=0.028964 \mathrm{~kg} \mathrm{~mol}^{-1}$ is the molar mass of air, and $\bar{z}[i]$ and $\bar{T}[i]$ are the mean altitude and the mean temperature (K) between the levels $i$ and $i+1$. The pressure profile is a retrieved parameter although it is not a direct product of the inversion computation (Eq. 5). Note that it could have been retrieved along with other parameters by adding the hydrostatic equilibrium equation as an additional constraint of the inversion.

The implementation of the inversion procedure is presented in the flowchart in Fig. 3. The Marquardt scheme consists of two nested loops: the outer one, henceforth called "main loop" refers to subsequent steps of minimizing $\chi^{2}$ with updated values of $x$. The inner loop (red line) is used to optimize the Marquardt parameter $\gamma$ and is henceforth called "Marquardt loop". After the initialisation of parameters, the forward model is run to calculate the simulated measurements and their weighting functions, and to estimate $\chi^{2}$ (step 1). In step 2, the scaled vector $\eta$ is calculated and the counter of the Maquardt loop, used for optimizing gamma, is set to zero. The inversion is performed in step 3 according to Eq. (5), the retrieved vector is unscaled and the pressure profile is reconstructed (if needed) from the retrieved temperature. The forward model is computed for $\boldsymbol{x}_{i+1}$ and the new $\chi^{2}$ is estimated. If $\chi^{2}$ increases, the process enters the Marquardt branch (red line) to increase the value of $\gamma$ : the Marquardt loop counter is incremented, $\gamma$ is multiplied by 3 and the sequence of operations is repeated from step 3. If $\chi^{2}$ decreases but the stopping criteria of the iterative optimization of $\chi^{2}$ in the main loop (see below) are not yet fulfilled, the main loop counter is incremented, $\gamma$ is divided by 3 and the procedure is repeated from step 1 (outer loop in black). These operations are performed until the change in $\chi^{2}$ is less than 0.05 or the number of iterations is more than 12 in the main loop or more than 5 in the Marquardt loop. Although these stopping criteria are no convergence criteria in a mathematical sense, experience has shown that solutions with a final $\chi^{2}$ between 0.6 and 2 and a value of gamma below 0.5 are acceptable. Otherwise, a warning flag is raised. Note that the lower value of the $\chi^{2}$ is less than 1 because of the overestimation of the error in the measurement covariance matrix $\mathbf{S}_{y}$.

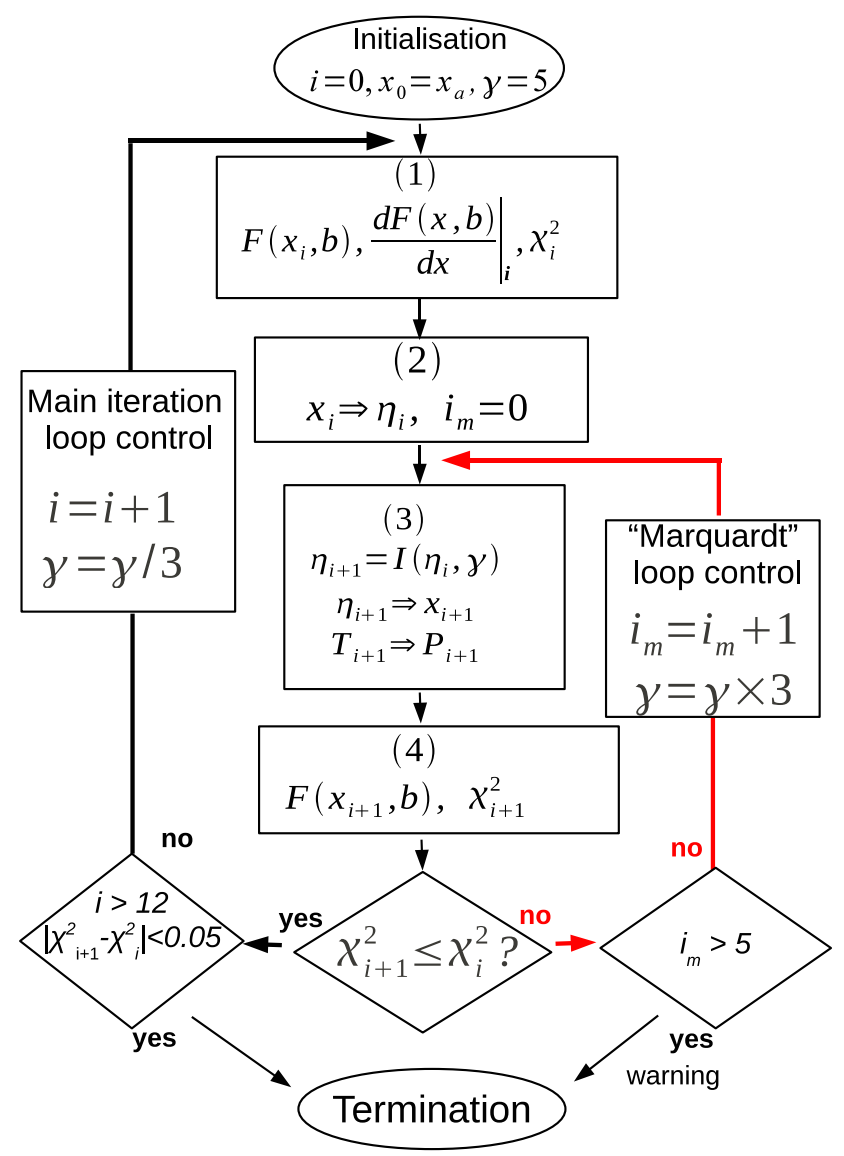

Fig. 3. Flowchart of the iterative inversion calculation. Step 1: the forward model and its Jacobian matrix, and the cost function (Eq. 2) are computed. Step 2: the retrieved parameters are scaled (Eq. 4) and the Marquardt loop counter is set to 0. Step 3: the inversion is performed (Eq. 5), the retrieved parameters are unscaled, and the pressure is derived from the retrieved temperature (Eq. 8). Step 4: the forward model and the cost function are estimated with the last estimate of the parameters. If the cost function decreases, the path is indicated by the black branch indicates the Gauss-Newton iteration loop including the decrease of the Levenberg/Marquardt parameter value. Otherwise, the Marquardt loop branch is used (red branch) where the Marquardt parameter $\gamma$ is increased.

\subsection{Characterisation of the errors}

\subsubsection{Method for the errors calculation}

The aim of this analysis is to evaluate the retrieval errors induced by the retrieved and uncertain parameters of each inversion process. The retrieval sub-grid size atmospheric variability is another important source of error since the atmospheric profiles are retrieved on coarse altitude grids with steps of $2-6 \mathrm{~km}$. This analysis takes into account the interprocess propagation and correlation of the errors. Parameters retrieved from one process can, indeed, be used in the following ones, causing the errors to propagate throughout 
the processes. Also, processes can share common measurements components, causing errors correlation. For example, the line-of-sight elevation angles and the $\mathrm{O}_{3}$ profile are retrieved from two different processes which use the same spectral line.

Regularizing the inversion calculation degrades the vertical resolution of the retrieved profiles. The retrieved vertical resolution is estimated from the width of the averaging kernel (Marks and Rodgers, 1993):

$$
\mathbf{A}=\left(\mathbf{K}^{T} \mathbf{S}_{y}^{-1} \mathbf{K}+\mathbf{S}_{\eta}^{-1}\right)^{-1} \mathbf{K}^{T} \mathbf{S}_{y}^{-1} \mathbf{K}
$$

Here $\mathbf{A}$ is the averaging kernel matrix calculated at the final iteration step of each process. Nevertheless, this definition of the vertical resolution makes sense only where the contribution from the a priori is small, otherwise the regularization error should be interpreted as a bias toward the a priori profiles. In order to evaluate the a priori contribution, we use the measurement response: $W=\sum_{j}(|\mathbf{A}[i, j]|)$ (Baron et al., 2002). In this study we consider only that the vertical range of a good retrieval is for altitudes where $|W-1|<0.2$.

The inversion performed in each process, is expressed as the non-linear inverse function $I$ of the difference between the measurement and the forward model:

$\hat{\boldsymbol{x}}=I\left(\boldsymbol{x}_{\mathrm{a}}, \boldsymbol{y}-\boldsymbol{F}\left(\boldsymbol{x}_{i}, \hat{\boldsymbol{p}}, \boldsymbol{b}\right)\right)$.

where $\hat{\boldsymbol{x}}$ is the estimate of the parameter $\boldsymbol{x}$ and $\boldsymbol{x}_{\mathrm{a}}$ is its a priori value, $\boldsymbol{y}$ is the measurement and $\boldsymbol{F}$ is the forward model, $\hat{\boldsymbol{p}}$ is the vector of parameters retrieved in a previous process and $\boldsymbol{b}$ is the vector of uncertain forward model parameters which are not retrieved. The vector $\boldsymbol{x}_{i}$ is initialised with $\boldsymbol{x}_{\mathrm{a}}$ and after convergence becomes equal to $\hat{\boldsymbol{x}}$. In the following $\boldsymbol{y}$ will not be the real measurement but a simulation depending on $\boldsymbol{x}, \boldsymbol{b}$ and $\boldsymbol{p}$. Note that $\boldsymbol{x}_{\mathrm{a}}$ and $\hat{\boldsymbol{x}}$ are defined on a retrieval grid with steps of $2-6 \mathrm{~km}$ and $\boldsymbol{x}$ is defined on a fine vertical grid with steps of $250 \mathrm{~m}$.

The retrieved error $\hat{\boldsymbol{\epsilon}}_{x}$ on $\hat{\boldsymbol{x}}$ is derived by linearising the inverse function with respect to the "uncorrect" parameters (Rodgers, 2000). It gives for Eq. (10):

$$
\begin{aligned}
\hat{\boldsymbol{\epsilon}}_{x} & =\left(\frac{\partial \boldsymbol{I}}{\partial \boldsymbol{y}}+\frac{\partial \boldsymbol{I}}{\partial \boldsymbol{F}} \frac{\partial \boldsymbol{F}}{\partial \hat{\boldsymbol{p}}} \frac{\partial \hat{\boldsymbol{p}}}{\partial \boldsymbol{y}}\right) \boldsymbol{\epsilon}_{y}+\left(\frac{\partial \boldsymbol{I}}{\partial \boldsymbol{F}} \frac{\partial \boldsymbol{F}}{\partial \boldsymbol{b}}+\frac{\partial \boldsymbol{I}}{\partial \boldsymbol{F}} \frac{\partial \boldsymbol{F}}{\partial \hat{\boldsymbol{p}}} \frac{\partial \hat{\boldsymbol{p}}}{\partial \boldsymbol{b}}\right) \boldsymbol{\epsilon}_{\mathrm{b}} \\
& +\left(\frac{\partial \boldsymbol{I}}{\partial \boldsymbol{y}} \frac{\partial \boldsymbol{y}}{\partial \boldsymbol{x}}+\frac{\partial \boldsymbol{I}}{\partial \boldsymbol{F}} \frac{\partial \boldsymbol{F}}{\partial \hat{\boldsymbol{p}}} \frac{\partial \hat{\boldsymbol{p}}}{\partial \boldsymbol{x}}\right) \boldsymbol{\epsilon}_{x}+\frac{\partial \boldsymbol{I}}{\partial \boldsymbol{F}} \frac{\partial \boldsymbol{F}}{\partial \hat{\boldsymbol{p}}} \hat{\boldsymbol{\epsilon}}_{p}
\end{aligned}
$$

where $\boldsymbol{\epsilon}_{y}$ is the error on the measurement, $\boldsymbol{\epsilon}_{\mathrm{b}}$ is the error on $\boldsymbol{b}, \boldsymbol{\epsilon}_{x}$ is the error on the first guess of $\boldsymbol{x}, \hat{\boldsymbol{\epsilon}}_{p}$ is the error on $\hat{\boldsymbol{p}}$ from errors that do not explicitly appear in the error budget. The latter can include, for example, the errors on the measurement that are not used in the current process. The terms depending on $\frac{\partial F}{\partial \hat{\boldsymbol{p}}}$ represent the inter-process error propagation and correlation.

The different terms can be estimated by perturbing the parameters of either the simulated measurement $(\boldsymbol{y})$ or the forward model $(\boldsymbol{F})$. In this study, we have chosen to perturb the measurement parameters. We used two methods, one based on finite difference calculation and the second based on statistical evaluation (e.g. standard deviation) of a set of retrieved profiles (100 simulations are performed for each parameter vector of interest). The choice of the method depends on the size of parameter vector to be perturbed. Perturbing a vector $\boldsymbol{\beta}$ which can be a part of either $\boldsymbol{x}, \boldsymbol{p}$ or $\boldsymbol{b}$, with uncorrelated components gives a variance of the retrieved state vector calculated as follow:

$\left\{\begin{array}{lcc}\hat{\boldsymbol{\sigma}}_{\beta}=\sum_{i}\left[I\left(\boldsymbol{y}\left(\beta[i]+\overline{\boldsymbol{\epsilon}}_{\beta}[i]\right)\right)-I(\boldsymbol{y})\right]^{2} & \text { for a finite difference analysis } \\ \hat{\boldsymbol{\sigma}}_{\beta}= & \operatorname{STD}\left\{I\left(\boldsymbol{y}\left(\boldsymbol{\beta}+\boldsymbol{\epsilon}_{\beta}\right)\right)\right\}^{2} & \text { for a statistical analysis }\end{array}\right.$

Here $\boldsymbol{y}$ is the perturbed simulated measurement, $\hat{\boldsymbol{\sigma}}_{\beta}$ is the retrieval error variance due to the vector $\boldsymbol{\beta}, \bar{\epsilon}_{\beta}[i]$ is the error on the $i$-th element of $\boldsymbol{\beta}, \boldsymbol{\epsilon}_{\beta}$ is a random vector of standard deviations $\overline{\boldsymbol{\epsilon}}_{\beta}$ and STD denotes the standard deviation of a set of retrieval outputs. To take into account correlations between the $\boldsymbol{\beta}$ components, independent perturbations are applied to the eigenvectors of the $\boldsymbol{\beta}$ covariance matrix. For example, the finite difference case becomes:

$\hat{\boldsymbol{\sigma}}_{\beta}=\sum_{i}\left(I\left(\boldsymbol{y}\left(\boldsymbol{\beta}+\mathbf{U} \overline{\boldsymbol{\epsilon}}_{\boldsymbol{\Lambda}}^{i}\right)\right)-I(\boldsymbol{y})\right)^{2}$,

where $\mathbf{U}$ and $\boldsymbol{\Lambda}$ are the eigenvectors and eigenvalues matrices of the $\boldsymbol{\beta}$ covariance matrix $\mathbf{S}_{\beta}\left(\mathbf{S}_{\beta}=\mathbf{U} \boldsymbol{\Lambda} \mathbf{U}^{T}\right)$, and $\overline{\boldsymbol{\epsilon}}_{\boldsymbol{\Lambda}}^{i}$ is a vector describing the error on the $i$-th eigenvector in the eigenvector space:

$\epsilon_{\Lambda}^{i}[j]=\left\{\begin{array}{cl}\sqrt{\Lambda[i, i]} & \text { if } j=i \\ 0 & \text { if } j \neq i .\end{array}\right.$

\subsubsection{Error assumptions}

The SMILES calibrated radiance (version 5) has a large error (between -1 and $10 \mathrm{~K}$ ) likely due to the non-correction of the radiometric gain non-linearity (Ochiai et al., 2011). To study this effect, the simulated measurement $\boldsymbol{y}$ is computed from a modified form of the forward model (Eq. 5):

$\boldsymbol{y}=C_{\mathrm{cal}, 0}+C_{\mathrm{cal}, 1} \times F(\boldsymbol{x}, \boldsymbol{p}, \boldsymbol{b})+N_{\mathrm{cal}}(F(\boldsymbol{x}, \boldsymbol{p}, \boldsymbol{b}))$

where $N_{\text {cal }}$ is a non-linear transformation to include the effect of the radiometric gain compression, and the coefficients $C_{\mathrm{cal}, 0}=1 \mathrm{~K}$ and $C_{\mathrm{cal}, 1}=1.01$ are the antenna spill-over and the radiometric gain error. The details about the calibration procedure and the gain compression errors are given in Appendix $\mathrm{C}$. The value of $C_{\mathrm{cal}, 0}, C_{\mathrm{cal}, 1}$ are upper limits deduced from the data, and the non-linear transformation is based on the latest calibration model provided by the instrument team.

Other errors are summarised in Table 5. They can be classified as random or systematic errors with respect to a single profile measurement. Systematic errors arise from the calibration parameters, the AOS channel width, neglecting the image band contribution, the dry air continuum and the spectroscopic parameters. Only the pressure-broadening parameters of the strongest lines in bands A and B are included in this study. 

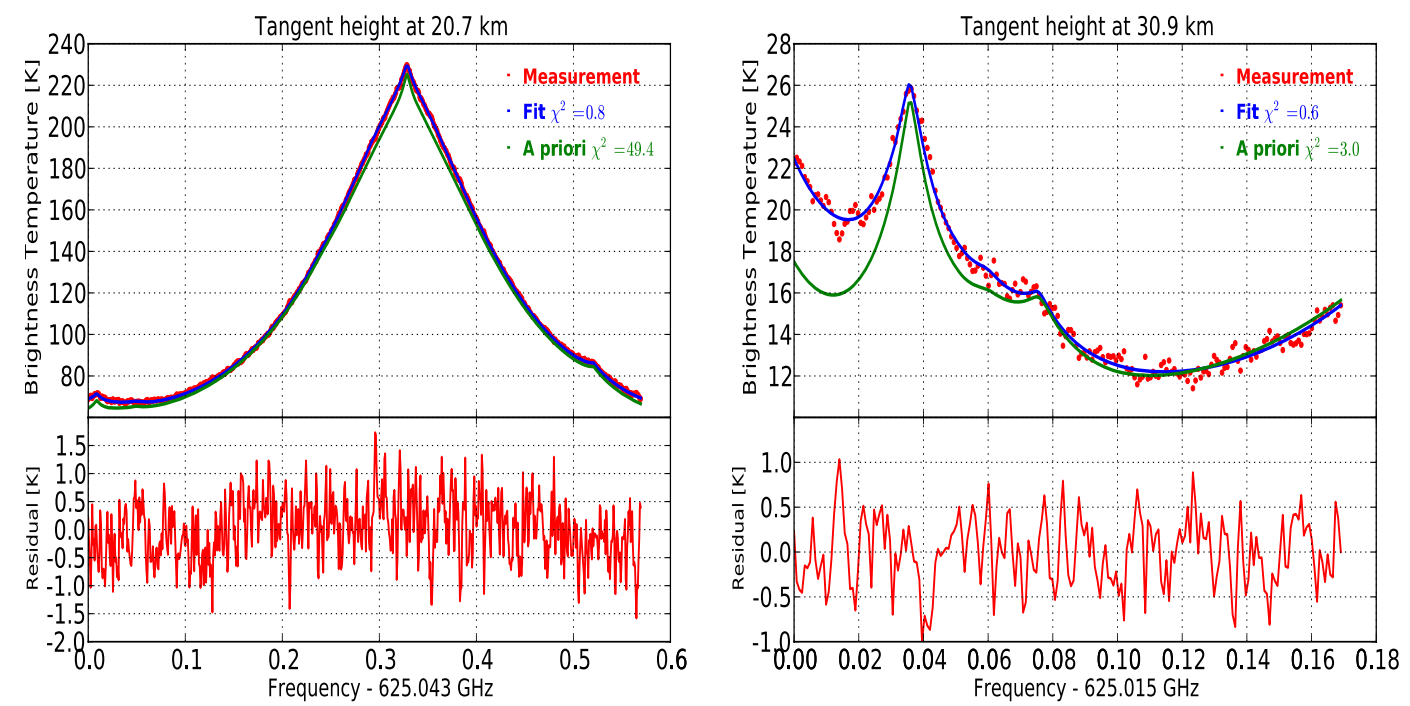

Fig. 4. Left panel: spectral line of $\mathrm{O}_{3}$ at $625.371 \mathrm{GHz}$ for a tangent height of $21 \mathrm{~km}$ measured in the window A-w 1 along with the a priori and fitted spectra. The lower panel shows the residual of the fit. Right panel: Spectral window A-w4 for a tangent height of $31 \mathrm{~km}$ (upper panel) and fit residual (lower panel). The weak $\mathrm{HOCl}$ line at $625.076 \mathrm{GHz}$ is located between two stronger lines of $\mathrm{O}_{3} \mathrm{v} 1,3$ and $\mathrm{OO}^{18} \mathrm{O}$ at 625.051 GHz and $625.091 \mathrm{GHz}$, respectively. Data are from a scan measured at 24:00 LT on 14 April 2010 at a latitude of $8^{\circ} \mathrm{N}$.

Table 5. Uncertainties assumed for single profile error estimation. The name of the parameters and the labels used for their identification in the figures are given in the parenthesis in the first column. The parameter $\gamma$ is for the line pressure-broadening parameter.

\begin{tabular}{|c|c|}
\hline \multicolumn{2}{|c|}{ Random errors } \\
\hline $\mathrm{O}_{3} \operatorname{VMR}\left(\mathrm{O}_{3}\right)$ & $10 \%$ of the a priori profile \\
\hline $\mathrm{HCl}$ VMR $(\mathrm{HCl})$ & $10 \%$ of the a priori profile \\
\hline Temperature (Tp) & $5 \mathrm{~K}$ \\
\hline Pressure (Pr) & $2 \%$ of the a priori profile \\
\hline Line of sight angles (LOS) & $0.007^{\circ}(300 \mathrm{~m})$ \\
\hline Measurement noise (y-noise) & $0.5 \mathrm{~K}$ \\
\hline \multicolumn{2}{|c|}{ Systematic errors } \\
\hline Calibration offset (CAL0) & $1 \mathrm{~K}$ \\
\hline Calibration gain (CAL1) & $1 \%$ \\
\hline Calibration gain compression $\alpha$ (CALN) & $1.515 \times 10^{-6}$ \\
\hline $\mathrm{O}_{3}-\gamma$ at $625.371 \mathrm{GHz}\left(\gamma-\mathrm{O}_{3}\right)$ & $2 \%$ \\
\hline $\mathrm{H}^{35} \mathrm{Cl}-\gamma$ at $625.901 \mathrm{GHz}(\gamma-35)$ & $5 \%$ \\
\hline $\mathrm{H}^{37} \mathrm{Cl}-\gamma$ at $624.964 \mathrm{GHz}(\gamma-37)$ & $5 \%$ \\
\hline $\mathrm{O}_{3} \mathrm{v} 1,3-\gamma$ at $625.051 \mathrm{GHz}(\gamma-\mathrm{v} 1,3)$ & $5 \%$ \\
\hline $\mathrm{OO}^{18} \mathrm{O}-\gamma$ at $625.091 \mathrm{GHz}(\gamma-18(1))$ & $5 \%$ \\
\hline $\mathrm{OO}^{18} \mathrm{O}-\gamma$ at $625.563 \mathrm{GHz}(\gamma-18(2))$ & $5 \%$ \\
\hline dry air continuum $\left(\mathrm{N}_{2}\right)$ & $20 \%$ \\
\hline Image band (IMB) & ON-OFF \\
\hline AOS filter width (AOS) & $10 \%$ \\
\hline
\end{tabular}

The random errors are the measurement thermal noise and the errors on the line-of-sight angles and on the atmospheric profiles. Uncorrelated errors of $0.005-0.01^{\circ}$ (errors of 200 $350 \mathrm{~m}$ on the tangent point altitude) are assumed on the lineof-sight angles (Shiotani et al., 2002, p.60). We have chosen to use an error of $0.007^{\circ}$. In reality, the value might be lower and more investigations have to be conducted to assess the actual line-of-sight angle errors.

\section{Performance of the retrieval procedure}

The objectives of this section are multiple. We first demonstrate and evaluate the capability of retrieving the line-ofsight elevation angles along with the $\mathrm{O}_{3}$ and temperature profiles from the strong $\mathrm{O}_{3}$ line at $625.371 \mathrm{GHz}$. We show that temperature is retrieved with low precision and accuracy and recommend to use pressure as vertical coordinates for data retrieved in the altitude range where the line-of-sight tangent altitudes are retrieved. We also show the value of reducing the width of the spectral windows containing weak lines in order to decrease the contamination from neighbouring lines. This issue is discussed through the error analysis for the $\mathrm{HOCl}$ retrieved profile.

The assumed uncertainties on the measurements and on the forward model parameters are given in Table 2. Retrieval errors have been assessed for all the parameters listed in this table but only the results with an impact larger than $1 \%$ are shown. The $\mathrm{O}_{3}, \mathrm{HCl}$ and $\mathrm{HOCl}$ profiles used for the error characterisation are shown in Fig. 4.

\subsection{Retrieval of the line-of-sight elevation angles}

Line-of-sight angles are retrieved from the processes A-w0 and B-w0 (Table 2). The spectral window is the same for both bands. It is centred at $625.371 \mathrm{GHz}$ on the strong $\mathrm{O}_{3}$ line, and extends over at least $200 \mathrm{MHz}$ on both sides of the 


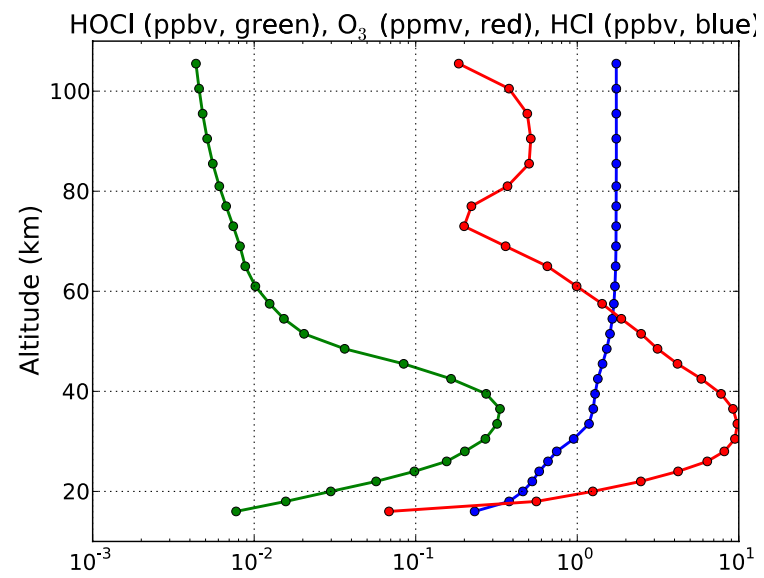

Fig. 5. VMR profiles of $\mathrm{HOCl}$ (green, ppbv), $\mathrm{O}_{3}$ (red, ppmv) and $\mathrm{HCl}$ (blue, ppbv) used for the sensitivity analysis.

line center. Figure 4 shows the $\mathrm{O}_{3}$ line measured at a tangent height of $20 \mathrm{~km}$. Given a pressure-induced line half-width of $2.198 \mathrm{MHz} / \mathrm{hPa}$, information can theoretically be retrieved from the line shape down to $\sim 90 \mathrm{hPa}$, i.e. down to an altitude of $\sim 17 \mathrm{~km}$. The spectral window setting also reduces the contamination from the neighbouring $\mathrm{HCl}$ lines. The profiles of $\mathrm{O}_{3}$, temperature, $\mathrm{HCl}$ isotopomers, $\mathrm{H}_{2} \mathrm{O}, \mathrm{HOCl}$ and $\mathrm{OO}^{18} \mathrm{O}$ are simultaneously retrieved on a sparse vertical grid of $3 \mathrm{~km}$ step below $30 \mathrm{~km}$ and $5 \mathrm{~km}$ above. They are considered as interfering parameters. Three $\mathrm{O}_{3}$ profiles are retrieved from the fits of the main line at $625.371 \mathrm{GHz}$ and of two minor lines of the molecule, respectively. The minor lines correspond to transitions in the first level $(v=1)$ of the $\mathrm{O}_{3}$ vibrational states $v=2$ and $v=(1,3)$, respectively.

A frequency offset for the full scan is also retrieved to account for the AOS channel frequency calibration and the $\mathrm{O}_{3}$ line frequency errors. In addition, a linear baseline (offset and slope) is retrieved for each spectrum to remove radiance offsets due to reflections in the instrument optics and to the antenna spill-over. The inversion iterative cycle usually converges in 5-7 iterations.

The averaging kernels and the measurement response (Fig. 6, left panel) show that the line-of-sight angles are retrieved between 18 and $60 \mathrm{~km}$. The high value of the measurement response and the well-peaked averaging kernels at $18 \mathrm{~km}$ show that the lowest limit of the retrieval altitude range could theoretically have been pushed further down. The lowest altitude of the retrieval grid has been chosen at $18 \mathrm{~km}$ in order to avoid errors from the continuum absorption modelling and contamination from ice particles scattering. The random errors (precision) of the angles retrieved from a single scan are between $0.004-0.005^{\circ}(\sim 200 \mathrm{~m}$ on the tangent point altitude) below $50 \mathrm{~km}$ (Fig. 7, left panel). Pressure is the dominant source of random errors. Errors from the measurement noise and other atmospheric parameters are lower than $0.002^{\circ}$. Above $50 \mathrm{~km}$, the random error

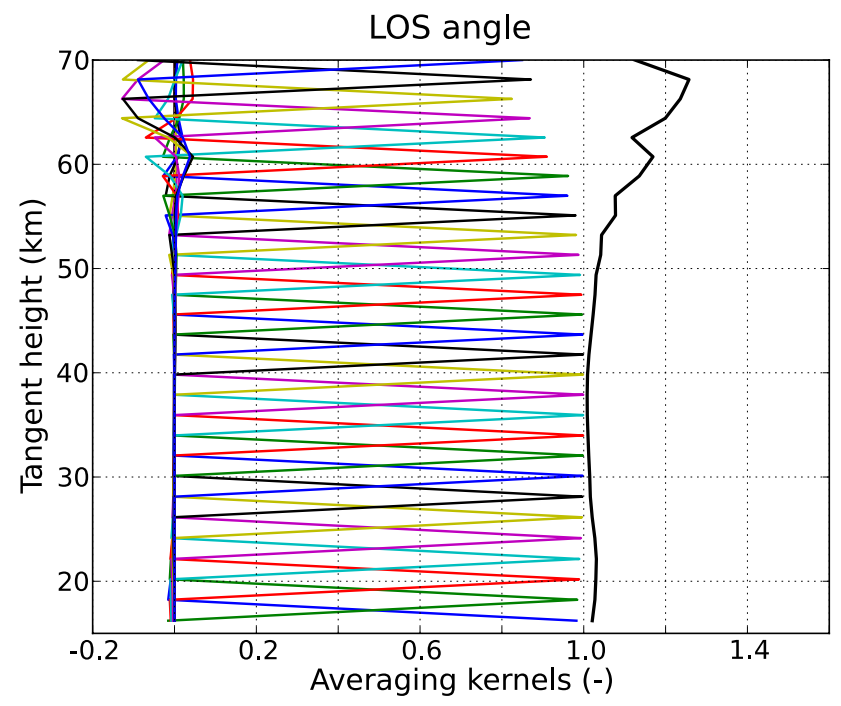

Fig. 6. Averaging kernels and measurement response (black line) for the retrieved line-of-sight elevation angle as a function of the tangent height.

due to the thermal noise becomes predominant and the total error is about $0.007^{\circ}$.

The right panel of Fig. 7 shows the systematic errors (accuracy) on the retrieved line-of-sight angles. Neglecting the non-linearity of the calibration gain induced a systematic error of $0.004-0.007^{\circ}$ (error of $160-280 \mathrm{~m}$ ). Between 30 and $50 \mathrm{~km}$, the error due to the $\mathrm{O}_{3}$ line pressure-broadening parameter $\left(0.003\right.$ to $\left.0.004^{\circ}\right)$ is the second source of systematic error. Above $50 \mathrm{~km}$, the systematic error increases strongly up to $0.008^{\circ}$, mainly due to the error on the AOS channel width. Below $20 \mathrm{~km}$, errors is estimated to $0.008^{\circ}$ due to non-linearity calibration gain and to the absorption continuum from dry air.

According to this results, the line-of-sight elevation angles is retrieved from the strong $\mathrm{O}_{3}$ line between $20-50 \mathrm{~km}$.

\section{2 $\mathrm{O}_{3}$ and temperature retrievals}

Temperature and $\mathrm{O}_{3}$ are simultaneously retrieved from the processes A-w1 and B-w1. The spectral characteristics of the widows are the same as for the w0 window used for the line-of-sight angles retrieval (Fig. 4, left panel). Spectra with line-of-sight tangent heights between $16-100 \mathrm{~km}$ are selected. The retrieval vertical grid for atmospheric parameters has a spacing of $2 \mathrm{~km}$ between $18-30 \mathrm{~km}, 3 \mathrm{~km}$ between $30-60 \mathrm{~km}, 4 \mathrm{~km}$ between $60-80 \mathrm{~km}$ and $6 \mathrm{~km}$ above. The retrieval grid corresponds to the vertical resolution estimated from a preliminary error analysis. A mean offset on the lineof-sight angles is also retrieved. However we found that in general this offset is small (less than $0.001^{\circ}$ ), indicating that the line-of-sight angles are correctly updated from process w0. Other retrieval settings such as other contaminating 

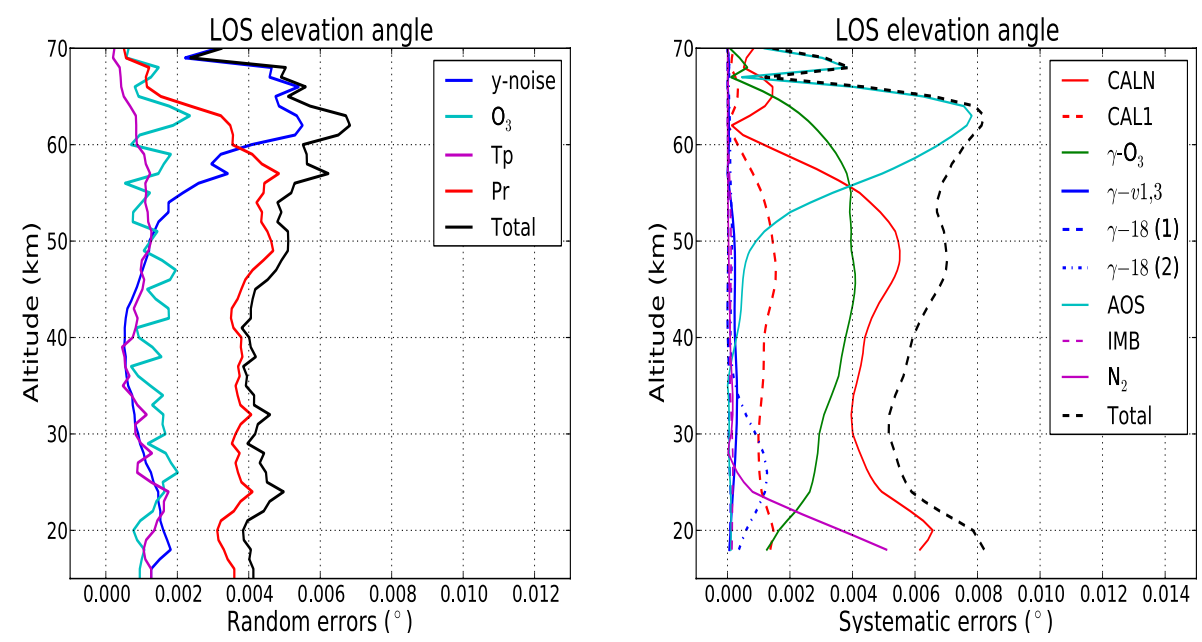

Fig. 7. Assessment of errors on the retrieved line-of-sight elevation angles from window A/B-w0. The random and systematic errors are shown in the left and right panels, respectively. The meaning of the labels and the assumed errors on the parameters are given in Table 5. The black line is the total error calculated as the root-sum-square of all sources of error.
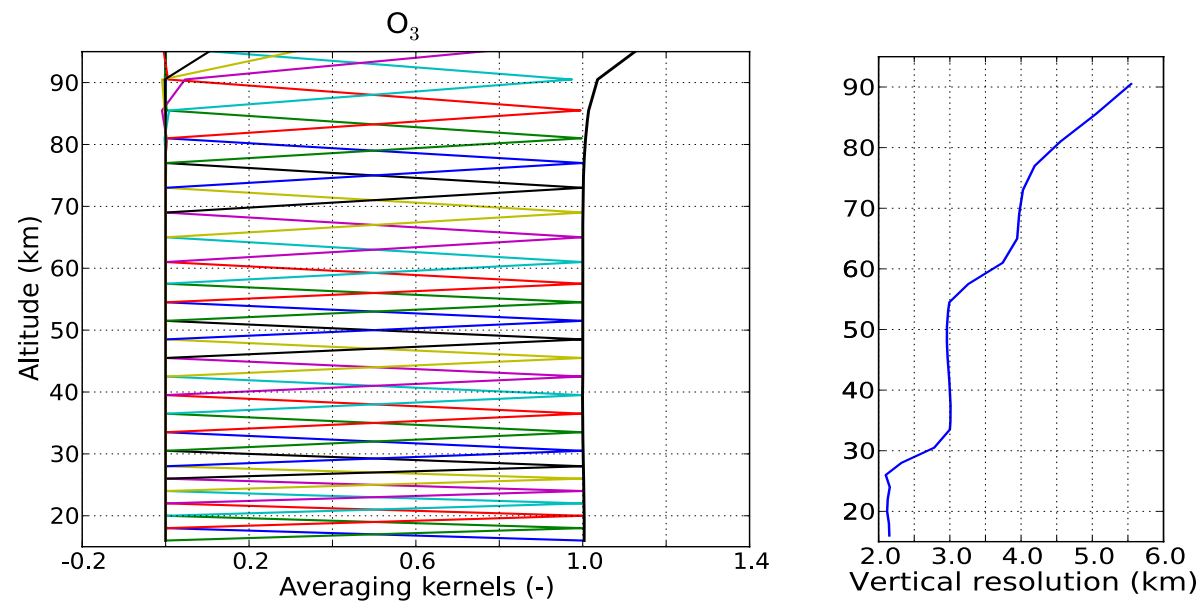

Fig. 8. Results for the $\mathrm{O}_{3}$ profile retrieved from window A/B-w1. Left panel: same as Fig. 6. Right panel: vertical resolution.

species and a priori and covariance matrices are the same as for process w0. The averaging kernels analysis shows that the $\mathrm{O}_{3}$ profile can be retrieved from 18 to $90 \mathrm{~km}$ with a vertical resolution close to the retrieval grid sampling (Fig. 8).

The random errors (precision) on the retrieved $\mathrm{O}_{3}$ profile are shown in the left panels of Fig. 9. The upper and the lower panels show the absolute and relative errors, respectively. Between $28-50 \mathrm{~km}$, the random error is $5-7 \%$ $(0.4-0.7 \mathrm{ppmv})$. The main error source is from the pressure profile. The errors for the line-of-sight angles are efficiently corrected and are responsible of less than $2 \%$ error on the $\mathrm{O}_{3}$ profile. Below $28 \mathrm{~km}$, the error on the line-ofsight angles becomes the main source of random error $(50 \%$ at $20 \mathrm{~km}$ ). However, it is smaller than the value obtained if the angles were not retrieved (Fig. 10). Between $50-75 \mathrm{~km}$, where it cannot be retrieved, the line-of-sight angles is the main error source $(20 \%)$. Above $75 \mathrm{~km}$, the $\mathrm{O}_{3}$ line intensity decreases strongly and the measurement noise becomes the main source of random error on the retrieved $\mathrm{O}_{3}$ profile.

The systematic errors (accuracy) on the retrieved $\mathrm{O}_{3}$ profile are presented on the right panels of Fig. 9. Between $20 \mathrm{~km}$ and $50 \mathrm{~km}$, a systematic error of $5-15 \%$ is found that is mainly induced by the non-linearity of the calibration gain. Below $30 \mathrm{~km}$, the error from the dry air continuum is significant $(5 \%$ at $25 \mathrm{~km})$, and becomes the main systematic error on the retrieved $\mathrm{O}_{3}$ profile below $21 \mathrm{~km}$. The error due to the $\mathrm{O}_{3}$ line pressure-broadening parameter is significant above $30 \mathrm{~km}(4-5 \%)$. Above $50 \mathrm{~km}$, the systematic error is $7-9 \%$, due to the errors on the AOS channel width, on the $\mathrm{O}_{3}$ line pressure-broadening parameter and on the non-linearity of the calibration gain. 

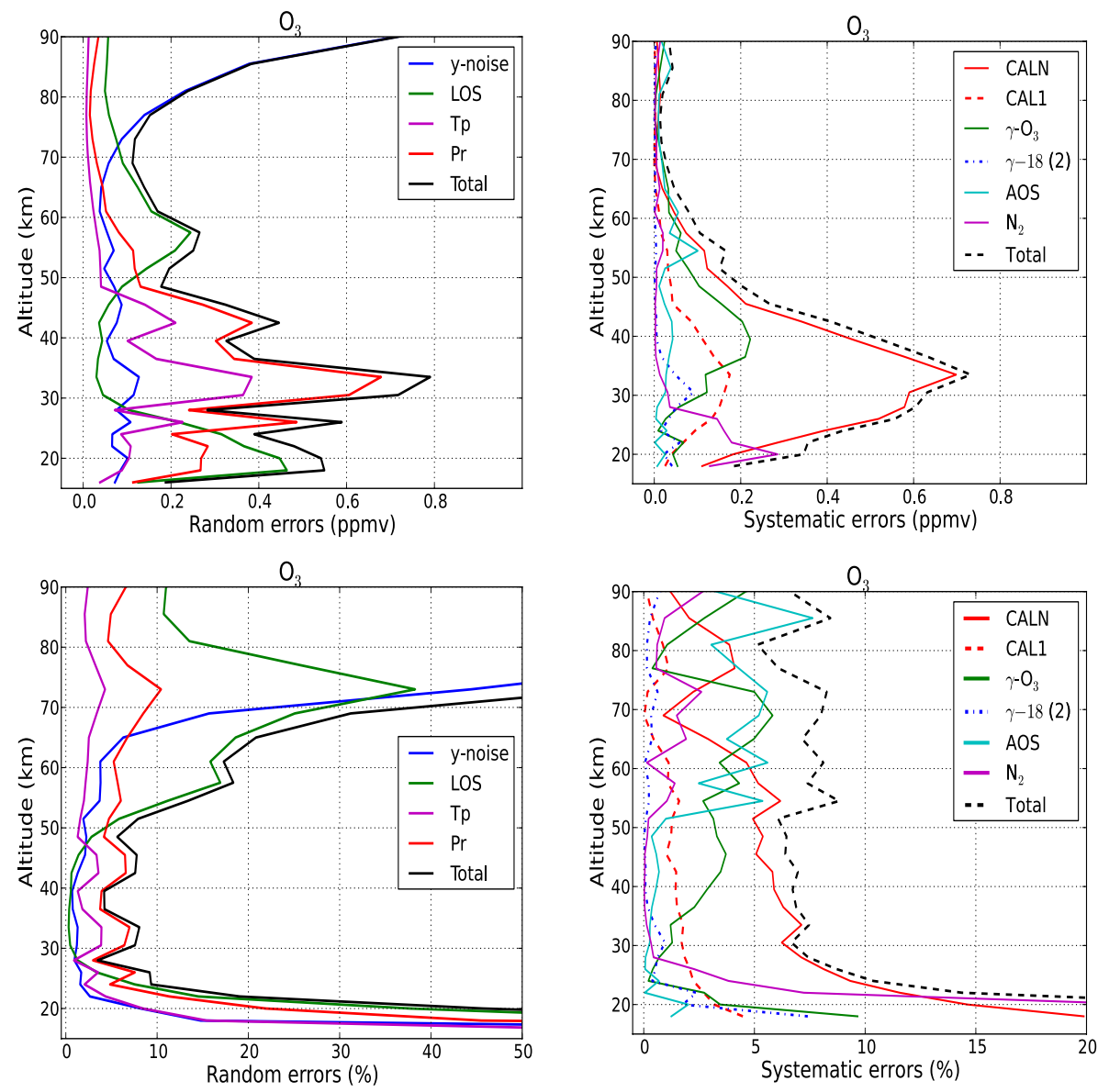

Fig. 9. Random (left panels) and systematic (right panels) errors on the $\mathrm{O}_{3}$ profile retrieved from window A/B-w1. The absolute and relative errors are shown in the upper and lower panels, respectively. Random errors are from the measurement noise (blue line), temperature profile (magenta line), pressure profile (red line), line-of-sight angle (green) and the total random error (black line). The meaning of the labels of the systematic errors and the assumed errors on the parameters are given in Table 5. The black line is the total error calculated as the root-sum-square of all sources of error.

Temperature is retrieved between $18-55 \mathrm{~km}$ with a vertical resolution of 6-14 km (Fig. 11). A random error of $2-10 \mathrm{~K}$ (Fig. 12) is induced by errors on the $\mathrm{O}_{3}$ and pressure profiles. The large range of the random error is due to oscillations on the temperature profiles retrieved from the simulated measurements. It is thus an error inherent to the inversion regularisation. A different regularisation should be implemented to improve the results.

As for $\mathrm{O}_{3}$, the non-linearity on the calibration gain (Fig. 12, left panel) is the main systematic error. It is reponsible of a large error of $8-10 \mathrm{~K}$. At $20 \mathrm{~km}$, the dry air continuum induces a significant systematic error of $2 \mathrm{~K}$.

The results for temperature are not satisfactory and must be improved. Consequently, atmospheric pressure is not derived from the retrieved temperature in version 2 of the processing. It becomes the main source of random errors on the retrieved $\mathrm{O}_{3}$ profile and on the line-of-sight angles.

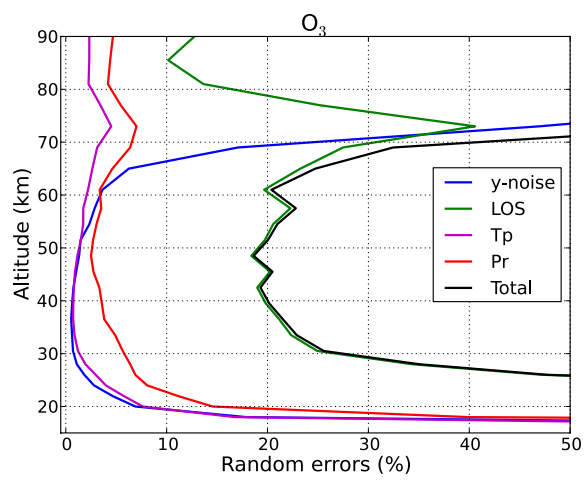

Fig. 10. Most significant random errors on a single $\mathrm{O}_{3}$ profile retrieved from A/B-w1 if the line-of-sight angles are not retrieved. The errors from the instrument noise (blue line), temperature (magenta), pressure (red) and line-of-sight angles (green line) are shown. The assumed uncertainties are given in Table 5 . 

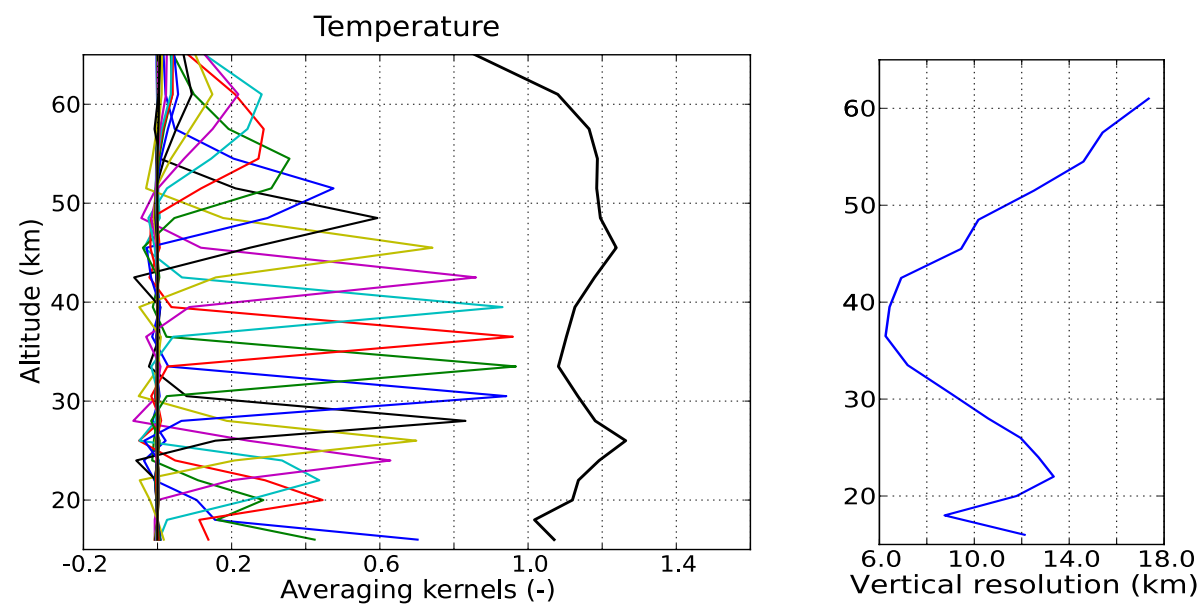

Fig. 11. Same as Fig. 8 but for the retrieved temperature profile.
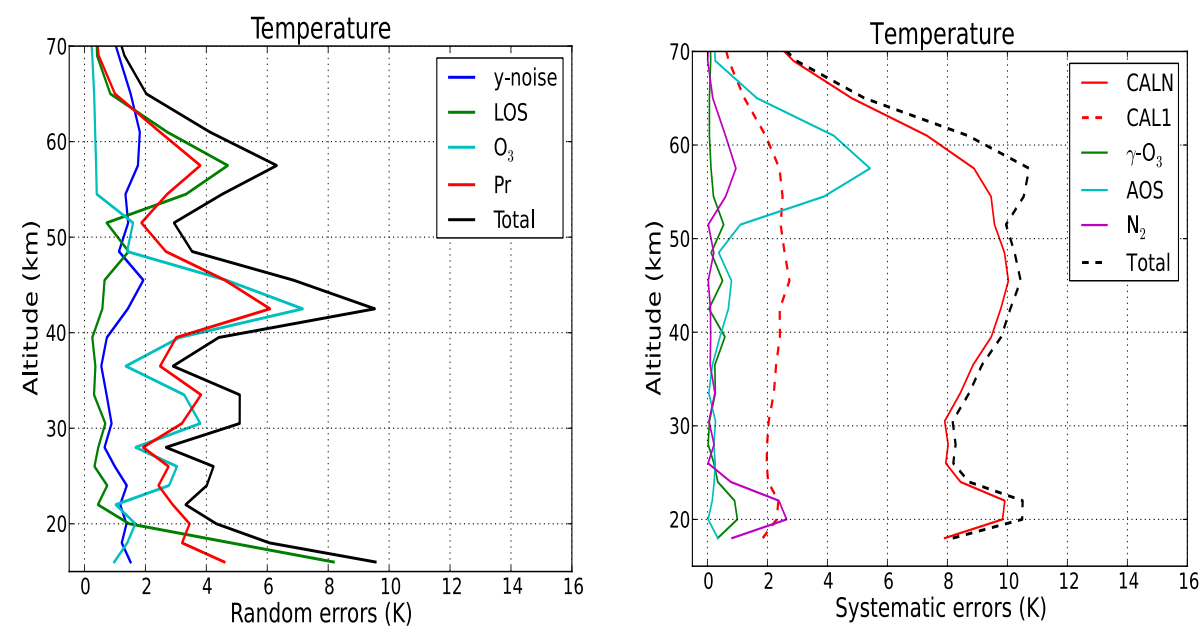

Fig. 12. Random (left panel) and systematic (right panel) errors on the temperature profile retrieved from window A/B w1. Random errors are from the measurement noise (blue line), $\mathrm{O}_{3}$ (cyan line), line-of-sight angle (green), the pressure profile (red line). The black line is the total error calculated as the root-sum-square of all sources of error. The meaning of the labels of the systematic errors and the assumed errors on the parameters are given in Table 5 .

\subsection{Use of pressure as vertical coordinates}

If the line-of-sight elevation angle is retrieved, the height of the tangent point is adjusted to the pressure level corresponding to the $\mathrm{O}_{3}$ line width. Since the pressure at the line-of-sight tangent point is correct, the error on the pressure profile should be considered as an error on the altitude and not on the pressure itself. As the molecular abundance is retrieved at the tangent point, it is then better to represent the retrieved molecular abundance on pressure levels instead of altitude levels. Figure 13 shows the $\mathrm{O}_{3}$ profile retrieved from a simulated measurement vector. The measurement vector was computed using atmospheric profiles (true profiles) from a winter mid-latitude climatology while the a priori profiles are from a tropical climatology. In addition, the true pressure profile was multiplied by 0.95 in order to highlight errors induced by the non-correction of the pressure profile using the retrieved temperature. A random noise of $0.4 \mathrm{~K}(1 \sigma)$ was added to the simulated radiances. As expected, the difference between the true and the retrieved $\mathrm{O}_{3}$ profiles is smaller if it is estimated on pressure levels (right panel) than on altitude levels (left panel). Between $30-50 \mathrm{~km}$, a difference of $4-6 \%$ remains due to the large error $(20-30 \%)$ on the assumed pressures at these altitudes.

\subsection{HOCl retrieval}

Two $\mathrm{HOCl}$ lines of similar intensity are measured at $624.378 \mathrm{GHz}$ and $625.075 \mathrm{GHz}$ (Fig. 1). The first line is measured in band $\mathrm{A}$ and the second is measured both in bands $\mathrm{A}$ and B. Although the line at $624.378 \mathrm{GHz}$ is less contaminated 

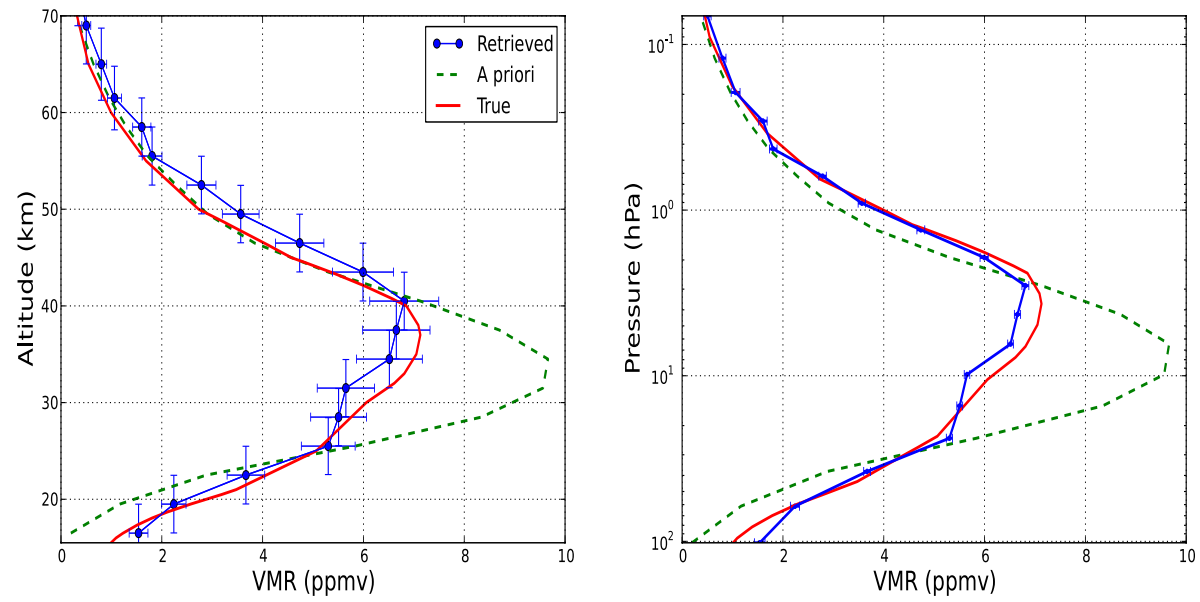

Fig. 13. Simulation of the A/B-w1 inversion process. The retrieved $\mathrm{O}_{3}$ profile is plotted as a function of altitude levels (left panel) and of pressure levels (right panel). Atmospheric profiles for simulating the measurement vector are from a winter mid-latitude climatology and from a tropical climatology for the reference/a priori profiles. In addition, the true pressure profile was multiplied by 0.95 and a noise of $0.4 \mathrm{~K}(1-\sigma)$ was added to the measurement vector. In the left panel the vertical bars indicate the full-width-at-half-maximum of the averaging kernels and the horizontal bars are the 1- $\sigma$ measurement noise and the pressure-induced error (Fig. 9). In the right panel the horizontal bars are for the $1-\sigma$ measurement noise.
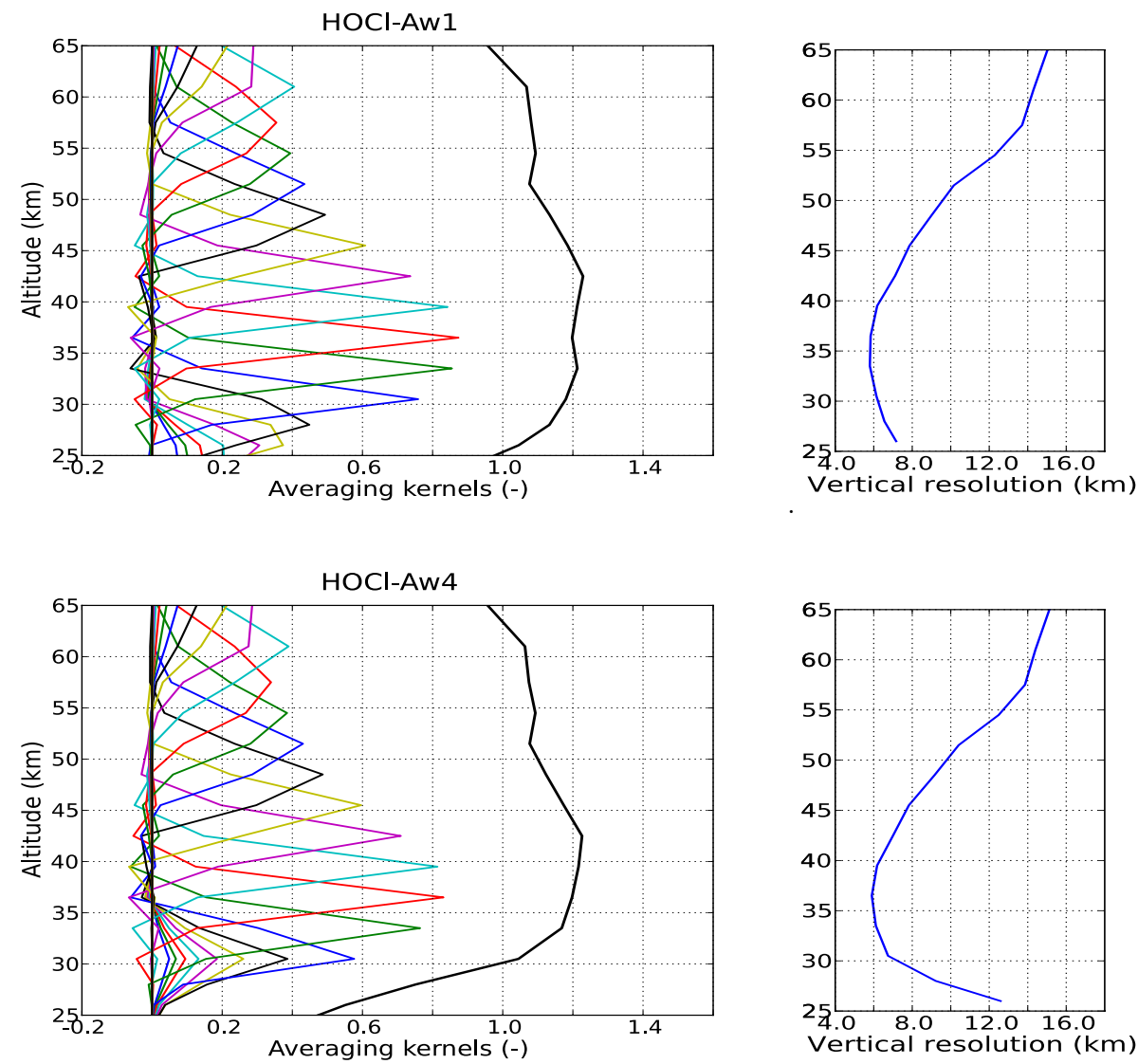

Fig. 14. Same as Fig. 8 but for the $\mathrm{HOCl}$ profile retrieved from windows A/B-w1 (upper row) and A-w4 or B-w3 (lower row). 

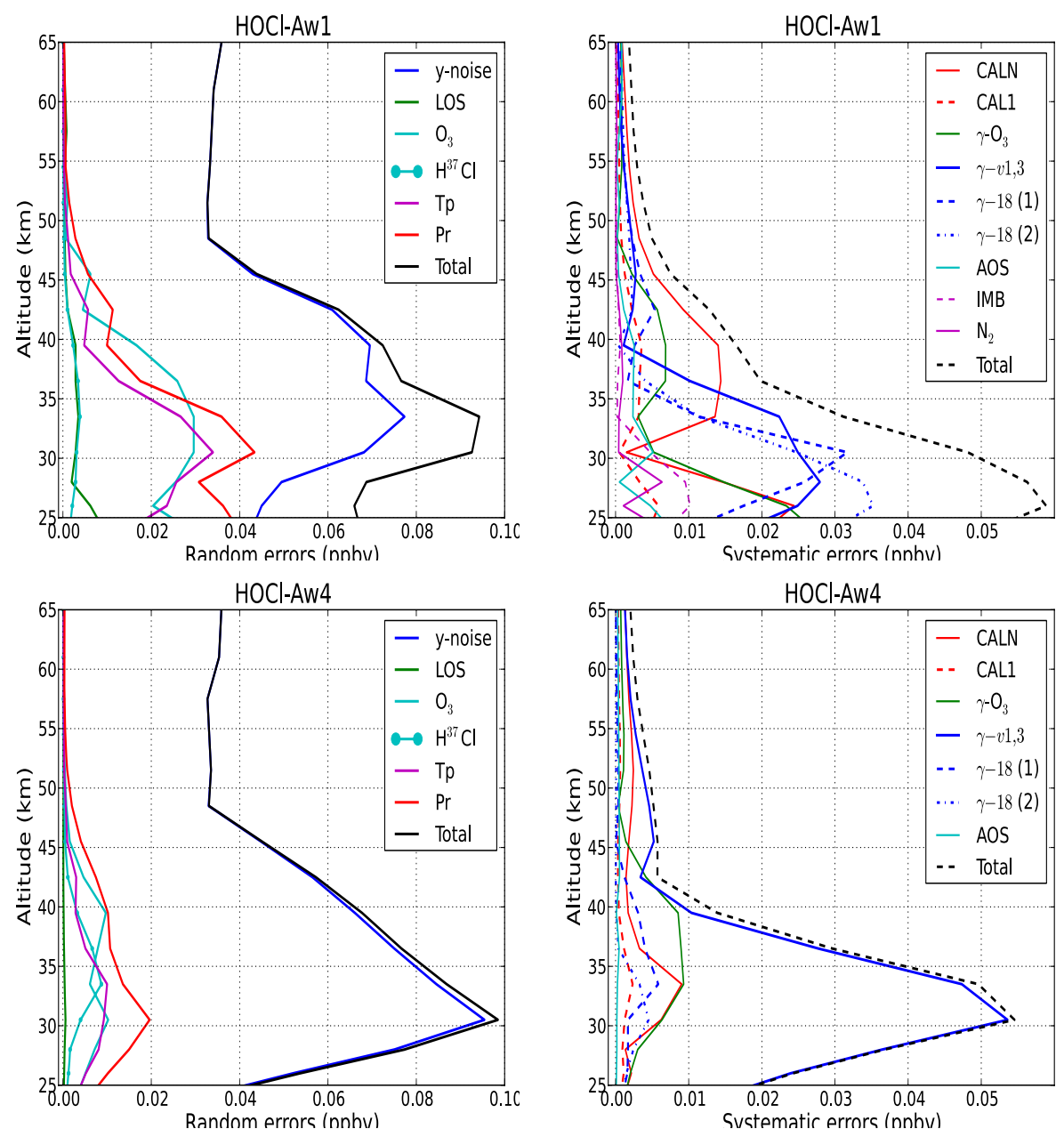

Fig. 15. Upper row: random (left panel) and systematic (right panel) errors on the HOCl profile retrieved from window A/B-w1. Lower row: Same for the $\mathrm{HOCl}$ profile retrieved from A-w4 or B-w3. The meaning of the labels on the systematic errors and the assumed errors on the parameters are given in Table 5 .

by other spectral lines, the retrieval quality has been found to be lower than for the line at $625.075 \mathrm{GHz}$. Hence only the second line is used in the current processing.

The line is measured in windows A-w1, B-w1, A-w4 and B-w3 (Fig. 4). The same frequency range of $\sim 200 \mathrm{MHz}$ width is used for A-w4 and B-w3.

The a priori error on the $\mathrm{HOCl}$ profile is set to $100 \%$ or $0.1 \mathrm{ppbv}$ (whichever is greater) over the whole altitude range. The retrieval setting is the same as the one for A/B-w1 described in Sect. 6.2. For the inversion of A-w4 and B-w3, a correlation scale-length of $6 \mathrm{~km}$ is used in the a priori covariance matrix. $\mathrm{HOCl}$ is retrieved simultaneously with $\mathrm{H}_{2} \mathrm{O}_{2}$, $\mathrm{OO}^{18} \mathrm{O}$ and $\mathrm{O}_{3} v_{1,3}$. A quadratic baseline is retrieved to account for radiance offset induced by the instrument and the emission from the out-of-window lines. A mean frequency offset over the full scan is also retrieved using the relatively strong $\mathrm{O}_{3} v_{1,3}$ line. As the characteristics of band A windows are similar to those of band $\mathrm{B}$ windows, only the results for band A (A-w1, A-w4) will be discussed.
From the analysis of the averaging kernel matrix, $\mathrm{HOCl}$ profile is retrieved from window A-w 1 between 25 and $60 \mathrm{~km}$ (Fig. 14, upper left panel) with a vertical resolution between 6 and $14 \mathrm{~km}$ (Fig. 14, upper right panel). The total random error on the $\mathrm{HOCl}$ retrieved profile (Fig. 15, upper left panel) is $0.05-0.09 \mathrm{ppbv}$ between 25 and $40 \mathrm{~km}$. The main error source is the measurement noise. Atmospheric parameters retrieved in previous retrieval steps also induce a significant random error of $0.03-0.05$ ppbv. The systematic error (Fig. 15, upper right panel) found for window w1 is $0.05 \mathrm{ppbv}$ at $25 \mathrm{~km}$ and decreases to below $0.005 \mathrm{ppbv}$ at $50 \mathrm{~km}$. The pressure-broadening parameters of nearby spectral lines and the non-linear calibration gain are the main uncertainties, with amplitudes between 0.01-0.04 ppbv.

From window A-w4, the vertical profile of $\mathrm{HOCl}$ is retrieved from 30 to $65 \mathrm{~km}$ (Fig. 14, lower panels). Hence, reducing the spectral range induces a truncation of the 25$30 \mathrm{~km}$ layer of the retrieval vertical range. Otherwise, the vertical resolution, the total random and total systematic 
Table 6. Polynomial coefficients used to calculate the channel response function for AOS units 1 and 2 (Eqs. A1 and A2).

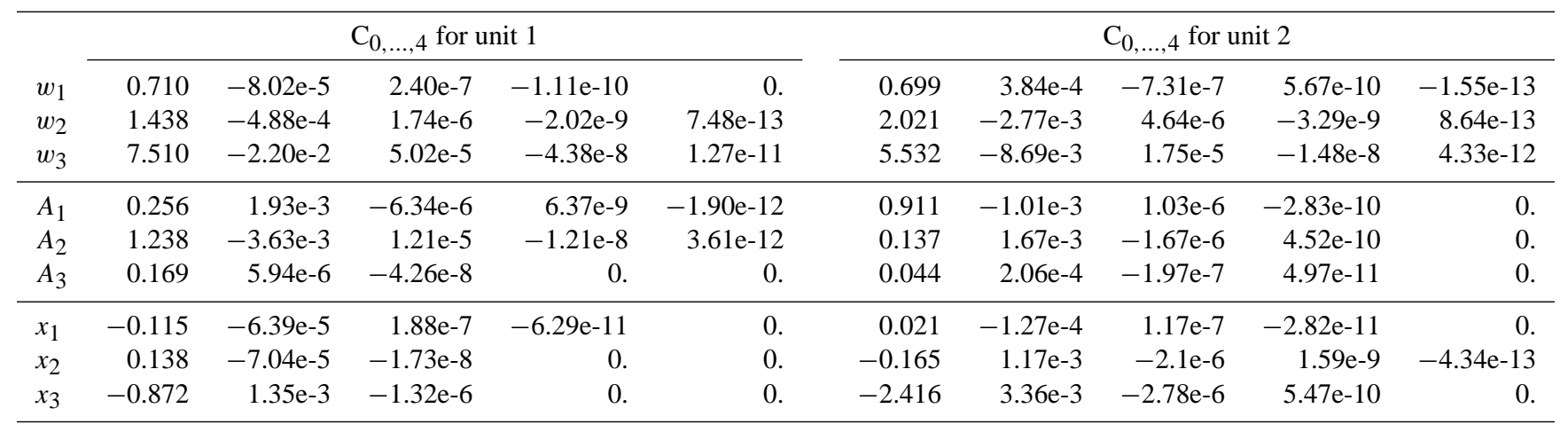

errors have similar values to those found for the inversion of A-w1. It is important to note that for A-w4, the random error is mainly due to measurement noise. Contamination from other atmospheric profiles (temperature, pressure, $\mathrm{O}_{3}$ ) is not significant (less than $0.02 \mathrm{ppbv}$ ). The systematic error is from the $\mathrm{O}_{3} v_{1,3}$ line pressure-broadening parameter. Errors from other lines and calibration are not significant (less than $0.01 \mathrm{ppbv}$ )

Using a narrower frequency bandwidth clearly decreases the contamination from other spectral lines, but slightly degrades the sensitivity at lowest altitudes. Those results are in agreement with previous studies for the Michelson Interferometer for Passive Atmospheric Sounding MIPAS limb emission spectroscopic experiment (von Clarmann and Echle, 1998).

\section{Conclusions}

We have presented version 2 of the retrieval algorithms for the SMILES level-2 research processing chain. The retrieval procedure is based on sequentially dependent steps. In each process, a dedicated analysis window containing only a subset of the spectral gridpoints of the full frequency band is used with an optimised retrieval setting. The forward model and the inversion method have been presented. The algorithms have been designed for the altitude range between $18-100 \mathrm{~km}$. It is not recommended to use the data retrieved below this range because uncertainties on the absorption coefficient continua and the radiances calibration lead to larger retrieval errors there. The line-of-sight angles are retrieved between 20 and $50 \mathrm{~km}$ from the strong $\mathrm{O}_{3}$ line, followed by retrieval of temperature and the $\mathrm{O}_{3}$ VMR profile. An error analysis has been conducted to show that the correlations between these parameters are low and that the three parameters can be retrieved from the chosen $\mathrm{O}_{3}$ line. The pressure profile is found to be the limiting parameter of the precision for the $\mathrm{O}_{3}$ profile and for the line-of-sight angles. However, the error induced by the pressure can significantly be decreased if the molecular VMR profiles are represented on pressure levels in the altitude range where the line-of-sight tangent altitudes are retrieved. Neglecting the non-linearity of the gain in the version 5 of the calibration procedure is the main systematic error. The next L2r version will use calibrated radiances including this effect.

An error analysis for the $\mathrm{HOCl}$ retrieved profile has been presented to illustrate the inversion of weak lines. It is shown that using narrow spectral windows around the line of interest allows to reduce the contamination from other atmospheric parameters, neighbouring spectroscopic lines and calibration errors.

Temperature is retrieved with low accuracy and precision and must be improved in future versions. Better calibration procedure and AOS channel response should increase the accuracy. Current works investigate ways to increase the temperature precision using a new regularisation scheme in the inversion calculation, and by joining the strong $\mathrm{HCl}$ and $\mathrm{O}_{3}$ lines in the same retrieval process.

Work is also being conducted to derive reliable information in the UT/LS about molecular abundances $\left(\mathrm{H}_{2} \mathrm{O}, \mathrm{O}_{3}\right.$ and $\mathrm{HCl})$ and on ice content. The retrieval of horizontal wind in the stratosphere and mesosphere along the line-of-sight direction is also under investigation.

\section{Appendix A AOS filter shape}

The AOS channel response function parametrisation in version 2 of the L2r chain has been provided before launch by the instrument teams. For both AOS units, the response function $g^{\mathrm{AOS}}(v)$ is defined by three Gaussian functions:

$$
g^{\mathrm{AOS}}(v)=\sum_{i=1,3} \frac{A_{i}}{w_{i} \sqrt{(2 \pi)}} \exp \left[-2\left(\frac{v-x_{0, i}}{w_{i}}\right)^{2}\right],
$$

where $v$ is the frequency in $\mathrm{MHz}$. 
Table A1. Side band response parameters for the lower side band (LSB) and upper side band (USB) (Eq. B1). The parameters $a$ and $v_{0}$ vary with the temperature of the Ambient Temperature Optics (AOP).

\begin{tabular}{lll}
\hline & Lower side band (LSB) & Upper side band (USB) \\
\hline$m$ & 0.00398 & 0.00470 \\
$\nu_{0}(\mathrm{GHz})$ & $-2.888012 \times 10^{-4} T_{\mathrm{AOP}}^{2}+0.0253396 T_{\mathrm{AOP}}+624.75733$ & $0.0085865 T_{\mathrm{AOP}}+648.75572$ \\
$a$ & $-2.90103 \times 10^{-7} T_{\mathrm{AOP}}+0.00003150$ & $-3.30717 \times 10^{-7} T_{\mathrm{AOP}}+0.00006756$ \\
\hline
\end{tabular}

The amplitude $\left(A_{i}\right)$, the width in $\mathrm{MHz}\left(w_{i}\right)$ and the center in $\mathrm{MHz}\left(x_{i}\right)$ are computed for each channel $j=1 \ldots 1728$ using polynomial coefficients $C_{\mathrm{p}}$

$X[j]=\sum_{\mathrm{p}=0,4} C_{\mathrm{p}} \cdot(j-1)^{\mathrm{p}}$,

where $X$ can be one of the Gaussian parameters $A_{i}$ or $w_{i}$ or $x_{i}$. The values of the coefficients $C_{\mathrm{p}}$ are given in Table A 1 .

Large errors on the AOS filter shape have been identified from the analysis of retrieved temperature or line-of-sight angles from spectra measured in the upper stratosphere. Ozeki et al. (2011) have estimated that the channel width $\left(w_{i}\right)$ of AOS units 1 and 2 should be multiplied by 0.7 and 1.1, respectively. These corrections are applied in the version 2 of the $\mathrm{L} 2 \mathrm{r}$ chain. The multiplicative factors have been derived from the temperature retrieval and, thus, are representative of errors on channels close to the strong $\mathrm{O}_{3}$ line center. Outside of this spectral domain the response function remains uncertain.

The response function is calculated for each channel on a frequency grid of $13 \mathrm{MHz}$ width, sampled in $0.1 \mathrm{MHz}$ steps within $2.5 \mathrm{MHz}$ range from the channel center and in $0.4 \mathrm{MHz}$ steps outside. Note that the response function is not symmetric and that the channel frequency calculated from the comb spectrum is assumed to correspond to the mean frequency over the channel $13 \mathrm{MHz}$ bandwidth weighted by the response function.

\section{Appendix B \\ Side band filter}

The upper and lower sideband rejection ratios (Eq. 1) are calculated using the equation (Ochiai et al., 2008):

$R^{X}(v)=m^{X}\left(v-v_{0}^{X}\right)^{2}+a^{X}$

where $X=\mathrm{LSB}$ or USB. The value for each parameter is given in Table A1.

The sideband rejection function depends on the temperature of the optics that varies between $16-22^{\circ} \mathrm{C}$. The image band contamination is less than $1 \%$ and the estimation of its intensity is done with less accuracy than in the main band, in order to minimize the CPU consumption.

\section{Appendix C \\ Radiometric gain compression error}

The raw radiometer outputs $C$ (ADU) depend on the input signal $T(\mathrm{~K})$ as follows (Ochiai et al., 2011):

$C=G(1-\alpha\langle C\rangle)\left(T_{\mathrm{rec}}+T\right)$,

where $G$ is the radiometric gain, $\alpha=1.515 \times 10^{-6}$ is the gain compression, $\langle C\rangle$ is the mean value of the AOS output and $T_{\text {rec }}=300 \mathrm{~K}$ is the receiver temperature. The value of the gain $G$ is set in order to give a cold load AOS output of $C_{\mathrm{c}}=14500 \mathrm{ADU}$, a typical value for SMILES measurements. The cold load signal is the brightness temperature of the cold sky, $T_{\mathrm{c}}=4 \times 10^{-4} \mathrm{~K}$.

In order to estimate the error caused by neglecting the gain compression factor, simulated atmospheric brightness temperatures are converted to AOS output using Eq. (C1). The brightness temperature $T_{1 \mathrm{~b}}$ as given in version 5 of the level$1 \mathrm{~b}$ data is calculated by converting the AOS counts while neglecting the gain compression:

$T_{1 \mathrm{~b}}=\frac{T_{\mathrm{h}}-T_{\mathrm{c}}}{C_{\mathrm{h}}-C_{\mathrm{c}}} \times\left(C-C_{\mathrm{c}}\right)+T_{\mathrm{c}}$

where $T_{\mathrm{h}}=275 \mathrm{~K}$ is the hot load brightness temperature and $C_{\mathrm{h}}$ is the hot load AOS output calculated using Eq. (C1).

Acknowledgements. Authors would like to thank S. Mizobuchi, K. Muranaga and S. Usui from Systems Engineering Consultants Co. (SEC) for their contribution to the development of the SMILES ground system in NICT. The work presented in the paper has been realized in close collaboration with the SMILES level 2 operational team in JAXA/ISAS: K. Imai, C. Mitsuda, T. Sano, M. Suzuki and C. Takahashi. We would also like to thank N. Livesey, W. Read and D. Wu from the MLS team for fruitful discussions, especially the ones about line-of-sight pointing correction. We also like to thank T. von Clarmann and the two reviewers for their valuable comments and suggestions for improving the manuscript.

Edited by: T. von Clarmann 


\section{References}

Baron, P., Merino, F., and Murtagh, D.: Simultaneous Retrievals of Temperature and Volume Mixing Ratio Constituents from Nonoxygen Odin Submillimeter Radiometer Bands, Appl. Optics, 40, 6102-6110, 2001.

Baron, P., Ricaud, P., de La Noë, J., Eriksson, P., Merino, F., Ridal, M., and Murtagh, D. P.: Studies for the Odin Sub-Millimetre Radiometer: II. Retrieval Methodology, Can. J. Phys., 80, 341356, 2002.

Baron, P., Mendrok, J., Kasai, Y., Ochiai, S., Seta, T., Sagi, K., Suzuki, K., Sagawa, H., and Urban, J.: AMATERASU: Advanced Model for Atmospheric TErahertz Radiation Analysis and Simulation, J. Nat. Inst. Inf. Commun. Tech., 55, 109-121, 2008.

Boissoles, J., Boulet, C., Tipping, R., Brown, A., and Ma, Q.: Theoretical calculation of the translation-rotation collision-induced absorption in $\mathrm{N}_{2}-\mathrm{N}_{2}, \mathrm{O}_{2}-\mathrm{O}_{2}$, and $\mathrm{N}_{2}-\mathrm{O}_{2}$ pairs, J. Quant. Spectrosc. Ra., 82, 505-516, doi:10.1016/S0022-4073(03)00174-2, 2003.

Carlotti, M. and Rodolfi, M.: Derivation of temperature and pressure from submillimetric limb observations, Appl. Optics, 38, 2398-2409, 1999.

Cazzoli, G. and Puzzarini, C.: Hyperfine structure of the $\mathrm{J}=1-0$ transition of $\mathrm{H}^{35} \mathrm{Cl}$ and $\mathrm{H}^{37} \mathrm{Cl}$ : improved ground state parameters: J. Mol. Spectrosc., 226, 161-168, doi:10.1016/j.jms.2004.03.020, 2004.

Drouin, B. J.: Submillimeter measurements of N2 and air broadening of hypochlorous acid: J. Quant. Spectrosc. Ra., 103 , 558564, doi:10.1016/j.jqsrt.2006.07.007, 2007.

Drouin, B. J. and Gamache, R. R.: Temperature Dependent Air Broadened Linewidths of Ozone Rotational Transitions, J. Mol. Spectrosc., 251, 194-202, doi:10.1016/j.jms.2008.02.016, 2008.

Ekström, M., Eriksson, P., Rydberg, B., and Murtagh, D. P.: First Odin sub-mm retrievals in the tropical upper troposphere: humidity and cloud ice signals, Atmos. Chem. Phys., 7, 459-469, doi:10.5194/acp-7-459-2007, 2007.

Harde, H., Katzenellenbogen, N., Grischkowsky, D.: Line-Shape Transition of Collision Broadened Lines, Phys. Rev. Let., 74, 1307-1310, 1995.

Hedin, A.: Extension of the MSIS Thermosphere Model into the Middle and Lower Atmosphere, J. Geophys. Res., 96, 11591172, 1991.

Hoshina, H., Seta, T., Iwamoto, T., Hosako, I., Otani, C., and Kasai, Y.: Precise measurement of pressure broadening parameters for water vapor with a terahertz time-domain spectrometer, J. Quant. Spectrosc. Ra., 109, 2303-2314, doi:10.1016/j.jqstr.2008.03.005, 2008.

Kikuchi, K. and Fujii, Y.: Flight Model Performance of 640-GHz Superconductor-Insulator-Superconductor Mixers for JEM/SMILES Mission, J. Infrared Millim. W., 31, 1205-1211, 2010.

Kikuchi, K., Nishibori, T., Ochiai, S., Ozeki, H., Irimajiri, Y., Kasai, Y., Koike, M., Manabe, T., Mizukoshi, K., Murayama, Y., Nagahama, T., Sano, T., Sato, R., Seta, M., Takahashi, C., Takayanagi, M., Masuko, H., Inatani, J., Suzuki, M., and Shiotani, M.: Overview and Early Results of the Superconducting Submillimeter-Wave Limb-Emission Sounder (SMILES), J. Geophys. Res., 115, D23306, doi:10.1029/2010JD014379, 2010.
Livesey, N. J., Snyder, W., Read, W., and Wagner, P.: Retrieval algorithms for the EOS Microwave Limb Sounder (MLS) instrument, IEEE T. Geosci. Remote, 44, 1144-1155, 2006.

Markov, V. N. and Krupnov, A. F.: Measurements of the Pressure Shift of the 110-101 Water Line at $556 \mathrm{GHz}$ Produced by Mixtures of Gases, J. Mol. Spectrosc., 172, 211-214, 1995.

Marks, C. J. and Rodgers, C. D.: A Retrieval Method for Atmospheric Composition from Limb Emission Measurements, J. Geophys. Res., 98, 14939-14953, doi:10.1029/93JD01195, 1993.

Mendrok, J., Baron, P., and Kasai, Y.: Studying the potential of terahertz radiation for deriving ice cloud microphysical information, vol. 7107, Remote Sensing of Clouds and the Atmosphere XIII, Proc. SPIE 7107, 710704, doi:10.1117/12.800262, 2008.

Murtagh, D. P., Frisk, U., Merino, F., Ridal, M., Jonsson, A., Stegman, J., Witt, G., Eriksson, P., Jiménez, C., Mégie, G., de La Noë, J., Ricaud, P., Baron, P., Pardo, J. R., Hauchecorne, A., Llewellyn, E. J., Degenstein, D. A., Gattinger, R. L., Lloyd, N. D., Evans, W. F. J., McDade, I. C., Haley, C. S., Sioris, C., von Savigny, C., Solheim, B. H., McConnell, J. C., Strong, K., Richardson, E. H., Leppelmeier, G. W., Kyrölä, E., Auvinen, H., and Oikarinen, L.: An Overview of the Odin Atmospheric Mission, Can. J. Phys., 80, 309-318, 2002.

Ochiai, S., Nishibori, T., Ozeki, H., Kikuchi, K., and Manabe, T.: Superconducting Submillimeter-Wave Limb-Emission Sounder on the International Space Station I: Radiometric and Spectral Calibration and Data Processing, J. Nat. Inst. Inf. Commun. Tech., 55, 83-94, 2008.

Ochiai, S., Kikuchi, K., Nishibori, T., Manabe, T., Ozeki, H., Mizukoshi, K., Ohtsubo, F., Tsubosaka, K., Irimajiri, Y., and Sato, M. S.: Performance of JEM/SMILES in orbit, Proceedings on 21st International Symposium on Space Terahertz Technology, p.179, 2010.

Ochiai, S., Kikuchi, K., Nishibori, T., Mizobuchi, S., Manabe, T., Mitsuda, C., and Baron, P.: Gain nonlinearity calibration of the SMILES receiver, IEEE International Geoscience and Remote Sensing Symposium, Sendai, http://igarss11.org/, last access: 1 June 2011.

Ozeki, H., Mizobuchi, S., Mitsuda, C., Sano, T., Suzuki, M., and Shiotani, M.: Response characteristics of radio spectrometers of the Superconducting Submillimeter-wave Limb-Emission Sounder (JEM-SMILES), IEEE International Geoscience and Remote Sensing Symposium, Sendai, http://igarss11.org/, last access: 1 June 2011.

Pardo, J. R., Serabyn, E., and Cernicharo, J.: Submillimeter atmospheric transmission measurements on Mauna Kea during extremely dry El Niño conditions: implications for broadband opacity contributions, J. Quant. Spectrosc. Ra., 68, 419-433, doi:10.1016/S0022-4073(00)00034-0, 2001.

Pickett, H. M., Poynter, R. L., Cohen, E. A., Delitsky, M. L., Pearson, J. C., and Müller, H. S. P.: Submillimeter, millimeter, and microwave spectral line catalog, J. Quant. Spectrosc. Ra., 60, 883-890, doi:10.1016/S0022-4073(98)00091-0, 1998.

Read, W. G., Shippony, Z., Schwartz, M. J., Livesey, N. J., and Snyder, W. V.: The clear-sky unpolarized forward model for the EOS aura microwave limb sounder (MLS), IEEE T. Geosci. Remote, 44, 1367-1379, doi:10.1109/TGRS.2006.873233, 2006. 
Reinecker, M.: The GEOS-5 data assimilation system: A documentation of GEOS-5.0, Tech Report 104606 V27 (NASA), 2008.

Rodgers, C. D.: Inverse Methods for Atmospheric Sounding: Theory and Practise, vol. 2 of Series on Atmospheric, Oceanic and Planetary Physics, World Scientific, 2000.

Rothman, L. S., Gordon, I. E., Barbe, A., Benner, D. C., Bernath, P. F., Birk, M., Boudon, V., Brown, L. R., Campargue, A., and Champion, J. P.: The HITRAN 2008 molecular spectroscopic database, J. Quant. Spectrosc. Ra., 110, 533-572, doi:10.1016/j.jqsrt.2009.02.013, 2009.

Rüeger, J. M.: Refractive Index Formulae for Radio Waves, FIG XXII International Congress Washington DC, http: //www.fig.net/pub/fig_2002/Js28/JS28_rueger.pdf (last access: 1 June 2011), 2002.

Sato, T. O., Mizoguchi, A., Mendrok, J., Kanamori, H., and Kasai, Y.: Measurement of the pressure broadening coefficient of the $625 \mathrm{GHz}$ transition of $\mathrm{H}_{2} \mathrm{O}_{2}$ in the submillimeter-wave region, J. Quant. Spectrosc. Ra., 111, 821-825, doi:10.1016/j.jqsrt.2009.11.022, 2010.

Schreier, F. and Kohlert, D.: Optimized implementations of rational approximations, a case study on the Voigt and complex error function, Comput. Phys. Commun., 179, 457-465, doi:10.1016/j.cpc.2008.04.012, 2008.

Shiotani, M., Masuko, H., and the SMILES Science Team: JEM/SMILES Mission Plan, Version 2.1, Tech. rep., National Space Development Agency (NASDA) and Communications Research Laboratory (CRL), http://smiles.tksc.jaxa.jp/document/ indexe.shtml (last access: 1 June 2011), 2002.

Takahashi, C., Ochiai, S., and Suzuki, M.: Operational retrieval algorithms for JEM/SMILES level 2 data processing system, J. Quant. Spectrosc. Ra., 111, 160-173, doi:10.1016/j.jqsrt.2009.06.005, 2010.
Urban, J., Baron, P., Lautié, N., Schneider, N., Dassas, K., Ricaud, P., and de La Noë, J.: Moliere (v5): a versatile forward- and inversion model for the millimeter and sub-millimeter wavelength range, J. Quant. Spectrosc. Ra., 83, 529-554, 2004.

Urban, J., Lautié, N., Le Flochmoën, E., Jiménez, C., Eriksson, P., de La Noë, J., Dupuy, E., Ekström, M., Amraoui, L. E., Frisk, U., Murtagh, D., Olberg, M., and Ricaud, P.: Odin/SMR limb observations of stratospheric trace gases: Level 2 processing of $\mathrm{ClO}, \mathrm{N}_{2} \mathrm{O}, \mathrm{HNO}_{3}$, and $\mathrm{O}_{3}$, J. Geophys. Res., 110, D14307, doi:10.1029/2004JD005741, 2005.

von Clarmann, T., and Echle, G.: Selection of optimized microwindows for atmospheric spectroscopy, Appl. Optics, 37, 76617669, 1998.

Waters, J. W., Froidevaux, L., Harwood, R. S., Jarnot, R. F., Pickett, H. M., Read, W. G., Siegel, P. H., Cofield, R. E., Filipiak, M. J., Flower, D. A., Holden, J. R., Lau, G. K., Livesey, N. J., Manney, G. L., Pumphrey, H. C., Santee, M. L., Wu, D. L., Cuddy, D. T., Lay, R. R., Loo, M. S., Perun, V. S., Schwartz, M. J., Stek, P. C., Thurstans, R. P., Boyles, M. A., Chandra, K. M., Chavez, M. C., Chen, G.-S., Chudasama, B. V., Dodge, R., Fuller, R. A., Girard, M. A., Jiang, J. H., Jiang, Y., Knosp, B. W., LaBelle, R. C., Lam, J. C., Lee, K. A., Miller, D., Oswald, J. E., Patel, N. C., Pukala, D. M., Quintero, O., Scaff, D. M., Snyder, W. V., Tope, M. C., Wagner, P. A., and Walch, M. J.: The Earth Observing System Microwave Limb Sounder (EOS MLS) on the Aura satellite, IEEE T. Geosci. Remote, 44, 1075-1092, doi:10.1109/TGRS.2006.873771, 2006.

Wu, D. L., Pickett, H. M., and Livesey, N. J.: Aura MLS THz Observations of Global Cirrus Near the Tropopause, Geophys. Res. Lett., 35, L15803, doi:10.1029/2008GL034233, 2008.

Yamada, M., Kobayashi, M., Habara, H., Amano, T., and Drouin, B. J.: Submillimeter-wave measurements of the pressure broadening of BrO, J. Quant. Spectrosc. Ra., 82, 391-399, 2003. 